\title{
Effects of Nanoparticle Enhanced Lubricant Films in Dynamic Properties of Plain Journal Bearings at High Reynolds Numbers
}

\author{
Mohammad Yaghoub Abdollahzadeh Jamalabadi \\ Dongguk University, Seoul, Department of Mechanical, Robotics and Energy Engineering, \\ Seoul, South Korea \\ abdollahzadeh@dongguk.edu
}

\begin{abstract}
Keywords: Nanoparticle; Film lubrication; Dynamic Properties; Plain Journal Bearings; High Reynolds; Turbulence
\end{abstract}

\begin{abstract}
The aim of this paper is numerical analysis of plain journal bearing with Nano particle added lubricating oil. The fluid film bearing is studied with the modified Reynolds equation which considered time dependent inertia effects at rotating speeds with the linearized turbulence. The research is performed for numerous nano-fluids include nanoparticles of $\mathrm{CuO}, \mathrm{TiO}_{2}, \mathrm{Ag}$ and $\mathrm{Cu}$ and SAE 20W50 as a base fluid. The time transient governing equations include the incompressible mass conservation equation, Navier-Stokes momentum equations for thin film lubrication, and full kinematic including shaft accelerations are solved numerically. Two cases of long and short bearings are studied with Sommerfeld and Gumbel boundary conditions. Linearized force coefficients such as mass, stiffness and damping factors are obtained for an ordinary journal bearing. The ordinary plain journal bearing velocity response and the rotor displacements when sudden forces applied by rigid rotor symmetrically is achieved. The results prove that using the nanoparticle enhanced lubricant causes higher mass coefficients, damping ratios and fluid effective stiffness.
\end{abstract}

\section{Introduction}

Lubricant nano-fluids are stable suspension of fine solid particles with the base fluid such as SAE oils. Accumulation of nanoparticles in nano-fluid can leads to dramatically pressure drop rise. Nowadays, lubricants perform numerous duties, that one of the principal of them is the engine solid parts lubricating, to lessen the friction and wear rate. Tichy developed conceptual design of different bearing configurations lubrication of impetuous loads in high Reynolds number for the first time [1]. The pressure gradient in nano-fluid and shear forces could be calculated from the velocity field crossways the lubricating nano-fluid film. Lubricant Oil rotor-dynamic properties are principally affected by additives that are supplemented to the base fluid oil to progress required properties. In recent times, nano-particles are correspondingly looking as if as a novel kind of lubricant additives, by reason of their special thermal and viscous properties. The tenacity of the present investigation is measuring the quantity of the aptitude of nano-particles as a type of the functionality to recover anti-wear characteristics and the thermal conduction capability and directing developed differences of the engine oils such as SAE, on its thermos-physical properties together with: the fluid kinematic viscosity, the pour point of the fluid and the flash point of the fluid. For this tenacity, metal ball particles, by means of the planetary ball grinder, were distributed inside the SAE 20W50. Then, examinations were complete for exploring stated possessions. Gotten consequences presented that the 18 percent increase of thermal conductivity by adding $0.1 \mathrm{wt} \%$ metal ball particles respect to the base oil will enhance the heat conduction while the wear reduced 5 percent.

Greases incorporating nanoparticle [2] or nanotubes [3] such as nano-crystalline silicone dioxide display and nanocrystalline titanium dioxide noteworthy decrease the wear and friction [4]. Potassium Tetraborate and Nano boric acid have also been used fruitfully as resistance tumbling additives in oil and greases [5]. Many other solutions [6] and materials [7] have used as lubricant while buyer hearsays advise that the toxicity properties of nano-technology and nano-fluids have not yet been completely discovered [8]. 
Tribological behavior of nanoparticles added fluids are investigated by many authors. Liu et al. [9] and Choi et al. [10] are considered copper nanoparticles tribological performance as extracts in grease oil on a tribological stressed wall surface. Lee et al. [11] are premeditated the tribological features of graphite nano lubricants. Other nanoparticle with various capping agent, shapes, base liquid, size such as multi-walled carbon nanotubes [12] fullerene nanoparticle [13-15] $\mathrm{Cu}$ nanoparticle [16] composite nanoparticles [17], Nano-Diamond nanoparticles [18] recommends that the nano-particles dissolved in various lubricant oil presented the starring part in the augmentation of lubrication [19].

In the usual Reynolds equality, both time-based and inertia terms (convective effects) are abandoned. This method is effortlessly defensible in examination for little reduced frequency number circumstances and small reduced Reynolds number [20]. Though, there is an important list of requests where both convective effects and time-based terms are significant and can disturb the study of nano-fluid film journal bearings. These contain low viscosity lubricants, high surface claims, tremor loads in journal bearings, squash film obstacles under unwary loads, etc.

The study of lubricant thin layers to comprise inertial terms in grease flicks has happened in an extended historical of time. Some original hard work to describe laminar to turbulent areas of lubricant flow was stated in the Pinkus and Sternlicht's research [21]. Such method was lengthy by Banerjee et al. [22] to procedure a further widespread type of Reynolds reckoning together with inertial relations. In a research by Chen and Chen [23] the belongings of inertial layer of fluid on limited length journal bearings examined and that research displays just minor contribution are understood for the journal bearings with modest number of Reynolds. A research by Tieu [24] demonstrated that the convective inertial terms has special contribution in a thrust bearing with limited length stridden and establish important paraphernalia close to the bearing's step.

Exhibiting of paraphernalia as a result of convective inertial and turbulence were presented by Neg [25], as well in a research by Neg and Pan [26], and a research by Elrod and Neg [27] by means of an eddy-diffusivity preparation together with pressure gradient and nonlinear shear terms which are encompassed in a long from of equation of Reynolds. That method was associated fine with current steady state investigational consequences and is applied in displaying software of bearing design frequently. Nevertheless, it merely embraces inertial convection possessions and does not consist of an action of time-based inertial terms.

A significant result by Constantinescu [28] research and his research by Galatuse [29-30] industrialized an alternative philosophy including turbulence effects and convective inertia special and by means of an averaged velocity in excess of the lubricant film method. They have gotten a comprehensive type of Reynolds equality counting the special contribution of the inertial convection. Averaged inertia technique of was correspondingly described by Szeri et al. [31] and is useful for the case of dampers with squeeze film where this effort protracted by San Andres and Vance [32]. In Ref. [33] a perturbation method is established to the answer of Reynolds equivalence together with primary order expressions in the condensed Reynolds number by Reinhardt and Lund. Nevertheless, this technique diverges for compact Reynolds number superior unity.

As stated above Tichy generalized the design of Reynolds calculation to take in impetuous forces initially [1]. Tichy and Bou-Said [1] cast-off the averaged velocity technique to get an extended Reynolds calculation consist of the special contribution of spontaneous heaps at the initial time. The extra effects take account of both squeeze acceleration terms plus additional squeeze velocity. They [1] offered a case in point studies to wholesome piles of squeeze film, small bearing pressure outlines, and few transient response of rotor schemes lacking and using the extra timebased and inertial convection expressions. A comprehensive debate on the properties of inertial effects of fluid on lubricant bearing steadiness observing that inertial special contribution are noteworthy in calculation of the rotor steadiness quantities is done by Kakoty and Majumadar [34]. As presented in recent researches [35-42] the inspiration of the ultrafine extracts on hydrodynamic oils lubrication and vibration and friction of the fluid flow film bearings greased with the with ultrafine spices. 
Inspiring the above mentioned research, it is interesting to see the effect of adding the effect of nano-fluid property to a turbulent Plain Journal Bearings at high Reynolds numbers. It will be helpful in some degree for the researchers to understand the tribological behavior of nanoparticles added fluids, and how to enhance the performance and service life of components, more compact designs. This study is offering the effect of nanoparticle addition to the base lubricant on rotordynamics parameters by solution of the continuity and Navier Stokes where the turbulence effects are linearized in calculations. Then by means of reduced Reynolds number, the equation of extended Reynolds is rewritten in non-dimensional form. First a short bearing is considered to extract the linearized mass, damping and stiffness coefficients for a number of reduced Reynolds number. At that moment, the stability threshold of rigid rotor is inspected for the turbulence properties and reduced Reynolds number. Succeeding, the contribution of nanoparticle fraction on the temporary reaction from the steady state of bearings is observed.

\section{Mathematical Model}

In Fig. 1 a lateral view of rotor with weight $2 \mathrm{~W}$ (W for each support) is shown from reference [2]. The rotor-bearing configuration of Fig. 1 includes a 2D dynamical system consisting of a mass, springs, and dampers. In this schematic under steady load, partial mass of the rotor, $M=W / g$, is focused at $O_{J S}$ which shown in Fig. 2 and cause to center of journal is moved from the center of bearing to the fixed working position. The center of mass will react by orbiting about $\mathrm{O}_{\text {JS }}$, its prompt orbital location represented by $\mathrm{O}_{\mathrm{J}}$. The additional stiffness and damping, as indicated in Fig. 1, causes lesser the critical speed underneath the value which considered for rigid supports, and decrease the vibration amplitude of the rotor.

This study has been done for water-based nano-fluids with nanoparticles of $\mathrm{Ag}, \mathrm{Cu}, \mathrm{CuO}$ and $\mathrm{TiO}_{2}$, the various eccentricity ratios, and the nanoparticles volume fraction of $0,0.01,0.02,0.03$ and 0.04 . Nanofluids at $16^{\circ} \mathrm{C}$ entered and the lateral surface of studied geometry is adiabatic. Thermophysical properties of SAE 20W50 as a base fluid are given in Table 1.

For the schematic of the system shown in Fig. 1, the mass conservation equation and the simplified incompressible Navier Stokes balances for in nano-fluid plain journal bearing are as:

$$
\begin{aligned}
& \frac{\partial u}{\partial x}+\frac{\partial v}{\partial y}+\frac{\partial w}{\partial z}=0 \\
& \frac{\partial p}{\partial x}+\rho\left(\frac{\partial u}{\partial t}+u \frac{\partial u}{\partial x}+v \frac{\partial u}{\partial y}+w \frac{\partial u}{\partial z}\right)-\mu \frac{\partial \tau_{x y}}{\partial y}=0 \\
& \frac{\partial p}{\partial y}=0 \\
& \frac{\partial p}{\partial z}+\rho\left(\frac{\partial w}{\partial t}+u \frac{\partial w}{\partial x}+v \frac{\partial w}{\partial y}+w \frac{\partial w}{\partial z}\right)-\mu \frac{\partial \tau_{z y}}{\partial z}=0
\end{aligned}
$$

Rotordynamic forecasts on industrial machines maintained by fluid film bearings dynamics momentum equalities that solve the directly above calculations that assume inertia of fluid can be totally neglected because the Reynolds number is very small. But here we consider the impact of temporal fluid inertia. Since in the examination, all expressions in the equation of Navier Stokes, comprising both the temporal inertia and convective parts are encompassed. The presence of the time-based inertial convection makes a liquid speeding up contributions in the Reynolds balance extended equation. The chief benefit of such origination is that lubricating layer in greased bearings by small magnitude viscidness oils that are substance under extraordinary thrust swing duties could be studied by such Reynolds extended equivalence. Over and done with a non-dimensional examination, Kokoty [34] and Szeri [31] presented that inertial convection terms standings turn out 
to be significant once the compact Reynolds number remains in magnitude order of unity ( $v \approx \omega c^{2}$ ). Here the same assumption of the Constantinescu [30] for the incorporation of thickness is used. By the integration of Navier Stokes the following equations are obtained :

$$
\begin{aligned}
& \frac{\partial q_{x}}{\partial x}+\frac{\partial q_{z}}{\partial z}+V=U \frac{\partial h}{\partial x} \\
& \rho\left(\frac{\partial q_{x}}{\partial t}+\frac{\partial I_{x x}}{\partial x}+\frac{\partial I_{x z}}{\partial z}\right)=-h \frac{\partial p}{\partial x}+\tau_{x y @ h}-\tau_{x y @ 0}+\rho U^{2} \frac{\partial h}{\partial x} \\
& \rho\left(\frac{\partial q_{z}}{\partial t}+\frac{\partial I_{x z}}{\partial x}+\frac{\partial I_{z z}}{\partial z}\right)=-h \frac{\partial p}{\partial z}+\tau_{z y @ h}-\tau_{z y @ 0},
\end{aligned}
$$

where $q_{x}, q_{z}$ and $I_{x x} I_{x z} I_{z z}$ characterize fluid flow volumetric amounts and inertial convection parameters, correspondingly and are defined as

$$
\begin{aligned}
& q_{x}=\int_{0}^{h} u d y=U_{p} h+\frac{1}{2} h U \\
& q_{z}=\int_{0}^{h} w d y=W_{p} h \\
& I_{x x}=\int_{0}^{h} u^{2} d y \\
& I_{x z}=\int_{0}^{h} u w d y \\
& I_{z z}=\int_{0}^{h} w^{2} d y
\end{aligned}
$$

$W_{p}$ and $U_{p}$ are the volume averaged speeds owing to fluid flow between two walls in axial direction and circumferential direction, correspondingly. As well the $V$ and $U$ in Eq. (8) are the velocities at the journal surfaces in radial course and circumferential route.

A usually recognized method is to assume a second order velocity outline (with a parabolic shape) over width in both axial direction plus circumferential direction as stated in Ref. [1], [30], and [34]. In such kind of techniques, the assumption is that the inertial expressions effects on the speed field are roughly insignificant. We keep an eye on Constantinescu's technique [30] which is founded on the principals of the mixing length theory for the ideal instability and disturbances. In the Ref. [30] Constantinescu's assumed a second order Poiseuille velocity shape as a base profile for the mixing length theory calculations of the turbulent system and undertake the dissimilar parameters for the turbulent and laminar systems; since

$$
\begin{aligned}
& I_{x x}=\alpha \quad U_{p}^{2} h+\beta \quad U^{2} h+\gamma \quad U_{p} U \quad h \\
& I_{x z}=U_{p} W_{p} h+\frac{1}{2} \quad U \quad W_{p} \\
& I_{z z}=\alpha \quad W_{p}^{2} h \\
& \alpha=\frac{6}{5}, \quad \beta=\frac{1}{3}, \quad \gamma=1 \\
& \alpha=1, \quad \beta=\left(0.25+\frac{0.885}{\operatorname{Re}^{0.367}}\right), \quad \gamma=1,
\end{aligned}
$$

where Eqs. (11 and 12) stipulate constants in turbulent and laminar rule, in turn. Into the bargain, the turbulent and laminar regime formulations for the shear rate are specified by [30] 


$$
\begin{aligned}
& \tau_{x y @ h}-\tau_{x y @ 0}=-\frac{k_{x} \mu}{h} U_{p}+\delta \rho\left(U_{p}+\frac{U}{2}\right)^{2} \frac{\partial h}{\partial x} \\
& \tau_{z y @ h}-\tau_{z y @ 0}=-\frac{k_{z} \mu}{h} W_{p}
\end{aligned}
$$

where the coefficients of Eq. (13) for the laminar regime is

$$
k_{x}=12, \quad k_{z}=12, \quad \delta=\frac{2}{15}
$$

and for the turbulent regime $(\operatorname{Re}>1000)$ is

$$
k_{x}=12+0.0136 \mathrm{Re}^{0.9} \quad k_{z}=12+0.0043 \mathrm{Re}^{0.96} .
$$

In journal plain bearing normal uses, the flows has the Reynolds number greater than $10^{3}$ order of magnitude and hence the normal measurements are not in the laminar fluid flow regime.

\section{Dynamic Investigation of Short Journal Bearing}

In this paper a complete dynamic and kinematic scrutiny of short journal bearings is explored. The analysis comprises the requirement of lubricating layer depth, speed and acceleration parts as a function of journal bearing limitations and parameters. Supposing that the main rotating shaft is flawlessly adjacent to the journal bearing, then the width of the lubricating layer can be find from

$$
h=-(\cos \theta X+\sin \theta Y)+c .
$$

The velocity components of a journal bearing wall from view point of an immovable coordinate system is spoken as

$$
\begin{aligned}
& \mathbf{V}_{s}=\left[\begin{array}{ll}
U & V
\end{array}\right]\left[\begin{array}{l}
\hat{n}_{\theta} \\
\hat{n}_{r}
\end{array}\right]= \\
& {\left[\begin{array}{ll}
R \omega-\dot{X} \sin (\theta)+\dot{Y} \cos (\theta) & -\dot{X} \cos (\theta)-\dot{Y} \sin (\theta)+\omega(X \sin (\theta)-Y \cos (\theta))
\end{array}\right]\left[\begin{array}{l}
\hat{n}_{\theta} \\
\hat{n}_{r}
\end{array}\right]}
\end{aligned}
$$

This balance (The over dot means the derivation is versus time) suggests that the movement on the wall of the journal bearing is begun with rotational speed ( $\omega$ signify the rotation influence) as well as the translational speed of it. Expressions comprising speeds at the midpoint of the shaft are rotational and the translational. For example, rotational components of circumferential speed and translational velocities can be re-written as

$$
\begin{aligned}
& U=U_{r} \hat{r}+U_{t} \hat{t} \\
& U_{t}=Y^{\cdot} \cos (\theta)-\dot{X} \sin (\theta) \\
& U_{r}=\omega R
\end{aligned}
$$

Compelling the time derivation of Eq. (17) versus time, the equation of speeding up of the surface wall of the shaft is obtained as

$$
\begin{aligned}
& \mathbf{a}_{s}=\left[\begin{array}{ll}
\dot{U} & V
\end{array}\right]\left[\begin{array}{l}
\hat{n}_{\theta} \\
\hat{n}_{r}
\end{array}\right]= \\
& {\left[-\ddot{X} \cos (\theta)-\ddot{Y} \sin (\theta)+R \omega^{2}-\ddot{X} \sin (\theta)+\ddot{Y} \cos (\theta)-\omega^{2}(X \sin (\theta)-Y \cos (\theta))\right]\left[\begin{array}{c}
\hat{n}_{\theta} \\
\hat{n}_{r}
\end{array}\right]}
\end{aligned}
$$


Over and done with Eqs. (16), (17), and (18), the former double expressions of continuity in Eq. (5) are shortened as

$$
-U \frac{\partial h}{\partial x}+V=-U_{t} \frac{\partial h}{\partial x}+\frac{\partial h}{\partial t}
$$

Presence of convective inertia consequences, in three nonlinear together PDE (i.e. Eqs. (5), (6), and (7)) those are hard to find their answer. Limited length mathematical approaches answer are computational overwhelming and costly in the time of calculation $[12,17]$. Therefore, the founded equalities is this paper will be applied on short length journal bearings, that make available adequate outfits to recognize the influence of extraordinary amount of Reynolds number spectacles on kinematic and kinetic performance of bearing lubrication, that is to say turbulence and inertia besides acceleration and velocity special effects. It is assumed that the $L / D$ ratio is lesser than 0.5 in small journal bearings that marks in the circumferential course the gradient of pressure is insignificant as

$$
\frac{\partial p}{\partial z} \gg \frac{\partial p}{\partial x}
$$

Therefore, the supposition of two opposing wall motion in the circumferential course is sensible (Couette flow) and ease the finding of the answer of equation (6), specifically

$$
\begin{aligned}
& q_{x}=\frac{1}{2} h U \\
& U_{p}=0
\end{aligned}
$$

assuming $\partial U_{r} / \partial x=0$ and replacing of Eqs. (18), (19), and (22) in the Eq. (5) (mass continuity balance) produces

$$
\begin{aligned}
& \frac{1}{2} \frac{\partial}{\partial x}\left(\begin{array}{ll}
U & h
\end{array}\right)+h \frac{\partial W_{p}}{\partial z}+\frac{\partial h}{\partial t}-\frac{\partial h}{\partial x} U_{t}=0 \\
& W_{p}=z \quad \Gamma(x, t)+C_{1} \\
& \Gamma(x, t)=-\frac{1}{h}\left(\frac{\partial h}{\partial t}+\frac{1}{2} U_{r} \frac{\partial h}{\partial x}+\frac{1}{2} h \frac{\partial U_{t}}{\partial x}-\frac{1}{2} U_{t} \frac{\partial h}{\partial x}\right),
\end{aligned}
$$

where $C_{1}$ is continuous value of integration. In the directly above equation, positions holding $U_{t}$ are in the order of $C / R$ which can be removed [2]. By requiring

$$
\Gamma(x, t)=-\frac{1}{h}\left(\frac{\partial h}{\partial t}+\frac{1}{2} U_{r} \frac{\partial h}{\partial x}\right)
$$

and substituting Eqs. (8), (10), (13), (23) and (24) in Eq. (7) and mathematically derivate just the one time respect to the $z$ parameter, the adapted Reynolds balance is got in form of

$$
\begin{aligned}
h^{3} \frac{\partial^{2} p}{\partial z^{2}}= & k_{z} \mu\left(\frac{\partial h}{\partial t}+\frac{1}{2} U_{r} \frac{\partial h}{\partial x}\right)-\rho\left(-U_{r} h^{2} \frac{\partial^{2} h}{\partial t \partial x}-\frac{1}{4} U_{r}^{2} h^{2} \frac{\partial^{2} h}{\partial x^{2}}\right. \\
& \left.+2 \alpha U_{r} h \frac{\partial h}{\partial x} \frac{\partial h}{\partial t}+\frac{1}{2} \alpha U_{r}^{2} h\left(\frac{\partial h}{\partial x}\right)^{2}-h^{2} \frac{\partial^{2} h}{\partial t^{2}}+2 \alpha h\left(\frac{\partial h}{\partial t}\right)^{2}\right)
\end{aligned}
$$

remind that the expressions in laminar regime as assumed by Tichy [1] is different from here as the 
constant behind the $U_{r}^{2} h^{2} \frac{\partial^{2} h}{\partial x^{2}}$ is $1 / 4$ in preference to $1 / 6$ and constant behind the $U_{r}^{2} h\left(\frac{\partial h}{\partial x}\right)^{2}$ must be $-3 / 5$ rather than $-23 / 30$ besides the RHS is function of $t$ and $x$. Meanwhile the periodic boundary of Eq. (25), in axial direction is

$$
p\left(z= \pm \frac{L}{2}\right)=0
$$

and with the Sommerfeld periodic boundary for peripheral direction

$$
p_{@ \theta=0,2 \pi}=0
$$

or under dynamic circumstances the peripheral pressure is assumed by the position of the filmcavity border and the Eq. (25) can be assessed by means of the Gumbel replacement

$$
p_{@ \theta=0, \pi}=0 .
$$

Since obtained forces produced on a journal bearing by the oil film of its bearings are nonlinear dependent of movement, acceleration and also velocity of the journal center place.

$$
F_{x, y}^{*}=f\left(\ddot{X}^{*}, \dot{Y}^{*}, X^{*}, Y^{*}, \dot{X}^{*}, Y^{*}\right)
$$

Effect of nanoparticle addition (such as $\mathrm{TiO}_{2}$ ) on the common oils is the increase of viscosity is generally the viscosity increase. In the evaluation of fluid properties in Eq. (25) the following relations are used

$$
\begin{aligned}
& \rho_{n f}=(1-\varphi) \rho_{\mathrm{f}}+\varphi \rho_{\mathrm{s}} \\
& \mu_{\mathrm{nf}}=\mu_{\mathrm{f}}(1-\varphi)^{-2.5}
\end{aligned}
$$

The model used for the properties of the lubricant is common and used in many papers.

\section{Dynamical Characteristics and Stability Analysis}

Accordingly, to compute the critical velocity and vibration amplitudes of mechanical rotors and to examine their steadiness against self-excited shakings, information of the rejoinder of the bearing oil film to journal displacements and speeds is vital. Outside a particular revolving promptness, plain journal bearings underneath continuous torque turn out to be rickety. To training the consequence of turbulence and inertia in high rotating shaft frequency on constancy, it is accepted in this paper that the technique of Kakoty [34], Allaire et al. [35], and Flack [36] to express the nonlinear equations of rigid rotor motion which maintained by plain journal bearing

$$
\left[\begin{array}{c}
F_{x}^{*} \\
F_{y}^{*}
\end{array}\right]=\bar{m} W^{*}\left[\begin{array}{c}
\ddot{X}^{*} \\
\ddot{Y}^{*}+1
\end{array}\right],
$$

where $\overline{\mathrm{m}}$ is the mass stricture that rolled by gyratory velocity and $W^{*}$ is the descendent peripheral torque on the shaft. Beneath a confident peripheral torque, a steady journal system is predicted to congregate to a similar precise steadiness location as

$$
\begin{aligned}
& \varepsilon_{0}=\left(X_{0}^{2}+Y_{0}^{2}\right)^{1 / 2}=f\left(W^{*}\right) \\
& \phi_{0}=\tan ^{-1}\left(\frac{Y_{0}}{X_{0}}\right)=f\left(W^{*}\right)
\end{aligned}
$$


The time-based inertia of fluid leads to a set of complete added mass constants and alterations to the damping constants. Therefore, here an amount of $\bar{m}$ is examined that the journal bearing develops unbalanced. For that goal, finished a mathematical perturbation technique, at equilibrium position the Newton equation parameters are obtained

$$
\left(M^{*}+M_{s}^{*}\right) \ddot{Q}^{*}+K^{*} Q^{*}+C^{*} \dot{Q}^{*}=0,
$$

where $M^{*}$ denote dimensionless mass, $C^{*}$ denote dimensionless damping, $K^{*}$ denote dimensionless stiffness matrices by reason of hydrodynamic forces, $Q^{*}=\left[X^{*}, Y^{*}\right]^{T}$ and $M_{s}^{*}$ is mass of the rotating shaft which given in matrix form as

$$
M_{s}^{*}=\bar{m} W^{*} \mathbf{I} \text {. }
$$

On the whole, hydrodynamic dynamic features of plain journal bearing are filled matrix, that is to say needing altogether components is not zero valued.

Several extra expectations about some particulars of the fluid flow field necessity are completed when inertia properties are careful. The external loads might be dimensionless redrafted concerning analyze the dynamic representative parameters (such as $K^{*}, C^{*}$ and $M^{*}$ ). The matrices of external loads displacements, velocities and accelerations are

$$
\begin{aligned}
& F^{*}=K^{*} Q^{*}+C^{*} \dot{Q}^{*}+M^{*} \ddot{Q}^{*} \\
& K^{*}=\left[\begin{array}{ll}
K_{x x}^{*} & K_{x y}^{*} \\
K_{y x}^{*} & K_{y y}^{*}
\end{array}\right]=\frac{\partial F^{*}}{\partial Q^{*}}=\left[\begin{array}{ll}
\frac{\partial F_{x}^{*}}{\partial X^{*}} & \frac{\partial F_{x}^{*}}{\partial Y^{*}} \\
\frac{\partial F_{y}^{*}}{\partial X^{*}} & \frac{\partial F_{y}^{*}}{\partial Y^{*}}
\end{array}\right] \\
& C^{*}=\left[\begin{array}{ll}
C_{x x}^{*} & C_{x y}^{*} \\
C_{y x}^{*} & C_{y y}^{*}
\end{array}\right]=\frac{\partial F^{*}}{\partial \dot{Q}^{*}}=\left[\begin{array}{ll}
\frac{\partial F_{x}^{*}}{\partial \dot{X}^{*}} & \frac{\partial F_{x}^{*}}{\partial \dot{Y}^{*}} \\
\frac{\partial F_{y}^{*}}{\partial \dot{X}^{*}} & \frac{\partial F_{y}^{*}}{\partial Y^{*}}
\end{array}\right] \\
& M^{*}=\left[\begin{array}{ll}
M_{x x}^{*} & M_{x y}^{*} \\
M_{y x}^{*} & M_{y y}^{*}
\end{array}\right]=\frac{\partial F^{*}}{\partial \ddot{Q}^{*}}=\left[\begin{array}{ll}
\frac{\partial F_{x}^{*}}{\partial \ddot{X}^{*}} & \frac{\partial F_{x}^{*}}{\partial \dot{Y}^{*}} \\
\frac{\partial F_{y}^{*}}{\partial \ddot{X}^{*}} & \frac{\partial F_{y}^{*}}{\partial \dot{Y}^{*}}
\end{array}\right]
\end{aligned}
$$

\section{Results}

An in- house code is developed and used in solution of Eq. (36) with the properties of Eq. (30-31) and for modified Eq. (25). A finite difference method has been used to solve the modified Reynolds equation in static and dynamical conditions and the dynamical calculations have been disentangled using Runge-Kutta method.

Figs. 4-6 present the various dynamic characteristic matrices as a function of equilibrium eccentricity location $(\varepsilon)$. As shown the effect of time-based inertia upsurges with the increase of shaft rotation rate. Its influence is also in need of on the added mass coefficients magnitude proportionate to its stiffness and damping magnitudes. Hence, time-based nano-fluid inertia special effects could be significant for high promptness, light rotor requests, over and above applications via low viscidness fluids, for instance water.

Numerical consequences expose the fact that effect of inertial forces on capacity of torque transport and approach angle in restricted the plain bearings is minor at modest amount of the compact Reynolds number. The inertial force's main consequence is the upsurge of volumetric flow rate from the sides. 
As expected, all of the mass constants are nil at zero values of reduced Reynolds number. Usually the mass matrix is diagonal dominate as that elements of mass matrices expressions are all progressive and greatly above the non-diagonal mass expressions. By increase of compact Reynolds number (a presentative of turbulence) the values of elements of mass matrices upsurge and increase. As well the diagonal elements of mass matrices are increasing rapidly with increase of eccentricity and all are positive. Furthermore, the elements of stiffness matrices increase by increase of eccentricity values where on the other hand are not as powerfully littered with increased turbulence and inertia at high frequencies. What's more, the elements of damping matrices increase by increase of eccentricity values where on the other hand are not as powerfully littered with increased turbulence and inertia at high frequencies even by increase of reduced Reynolds number the stability is increased.

In the design of fluid bearings, the bearing characteristic number $\left(S=(r c)^{2} \mu N / P\right)$, or Sommerfeld number, which is based on the radius of shaft, the clearance in radial direction, the total lubricant viscosity, the rotating shaft velocity, the bearing length, the applied external torques and forces, and diameter of the bearing. The number of Sommerfeld is used in Petroff's method of lubrication coefficient of friction analysis at small radial load. The Petroff's Law is stated the linear relation of friction coefficient with Sommerfeld number $\left(\mathrm{f}=2 \pi^{2} \mathrm{Sc} / \mathrm{r}\right)$.

Fig. 4 shows the added mass elements vs. equilibrium eccentricity, MRR and MRT top left and right, MTR and MTT bottom left and right, respectively. All decrease by increase of eccentricity except MTT which increase for case 2.

Fig. 5 presents the direct damping elements vs. equilibrium eccentricity, CRR and CRT top left and right, CTR and CTT bottom left and right of the all cases, respectively. As shown all analytical model damping elements increase by increase of eccentricity.

The supposition which may be pointed out is that the process provides acceptable consequences for almost all circumstances which might be come across in applied requests. A characteristic instance about the heaviness supply in the fluid flow film is exposed in Fig. 6. Fig. 6 displays the stiffness elements vs. equilibrium eccentricity, KRR and KRT top left and right, KTR and KTT bottom left and right, respectively. As shown all stiffness elements increase by increase of eccentricity.

Fig. 7 parades the stability graph, threshold angular velocity versus shaft rotation speed. As shown, critical frequency increases by increase of shaft rotation speed. There is no threshold for Case 1 while the highest critical velocity is for Case 2 with $20000 \mathrm{rpm}$.

In the case of an incompressible lubricant, each value of the eccentricity ratio resembles to an assumed value of the Sommerfeld number. Fig. 8 exhibits the stability graph, threshold angular velocity versus eccentricity ratio. As shown, threshold of critical frequency decreases by increase of eccentricity. There is no stability graph for Case 1 while the highest threshold angular velocity is for Case 2 with $10000 \mathrm{rpm}$ at eccentricity ratio. The value of threshold angular velocity for case 3 at eccentricity ratio of 0.1 is about $100000 \mathrm{rpm}$. Having found the threshold of instability, the safe condition of working condition is determined.

Fig. 9 presents the rigid rotor maintained by double finite length (short) bearings for dynamic analysis. The rigid rotor could be supported by any type of support such as two-lobe non-circular gas-lubricated journal bearing. To examine the performance of the rotor center in horizontal and vertical directions under the different working situations, the dynamic route, and the stability maps are presented.

Fig. 10 demonstrates the rigid rotor Orbits at bearing at $20000 \mathrm{rpm}$ in position space, velocity space, phase space, and displacement versus time. As shown the velocity and displacement vibrate around the static point and the phase diagram presents a right side deviation from the equilibrium point. Fig. 11 shows the effects of preload on analytical model. The preload produces similar consequences to the bearing with zero pre-load obtainable with the biggest change are the higher position of the orbits. Additionally the x component of movements is upper than the y constituent of it.

Fig. 11 demonstrates the rigid rotor phase diagram Orbits at bearing at 15000rpm in position space, velocity space, phase space, and displacement versus time. As shown the velocity and 
displacement vibrate around the static point and the phase diagram presents a right side deviation from the equilibrium point. As well the $\mathrm{x}$ component of displacements is higher than the $\mathrm{y}$ component of it. The increase in the displaced orbit to the right is increased constantly. The journal bearing demonstrations an upsurge in unpredictability that changes to a superior orbit with advanced speed. The plain bearing reaches the clearance circle, which previously seen and it is probably related to the lower pad moment of inertia.

The theory is then applied to the circumstance of a huge rotor simply supported by a short bearing, to which a big thoughtless load is practical in adding to the stable weight. Fig. 12 makes evident the rigid rotor path in bearing at $10000 \mathrm{rpm}$ in position space, velocity space, phase space, and displacement versus time. As shown the velocity and displacement vibrate around the static point and the phase diagram presents a right side deviation from the equilibrium point. As well the $\mathrm{x}$ component of displacements is higher than the y component of it.

Fig. 13 reveals the rigid rotor path in bearing at $5000 \mathrm{rpm}$ in position space, velocity space, phase space, and displacement versus time. As shown the velocity and displacement vibrate around the static point and the phase diagram presents a right side deviation from the equilibrium point. As well the $\mathrm{x}$ component of displacements is superior the y component of it.

Fig. 14 makes known the Added mass elements for nanoparticle added lubricant vs. equilibrium eccentricity, MRR and MRT top left and right, MTR and MTT bottom left and right, respectively. As shown all mass element increase by adding nanoparticles. An insignificant pressure drop penalty was bringing into being for all three volume fractions. Since nano-fluids reason slight or no consequence to pumping force for the reason that at actual little volume fractions the nanoparticles will not considerably upset the viscidness.

Fig. 15 discloses the Damping elements for nanoparticle added lubricant vs. equilibrium eccentricity, CRR and CRT top left and right, CTR and CTT bottom left and right, respectively. As shown all damping elements are increased by adding nanoparticles.

Fig. 16 divulges the Stiffness elements for nanoparticle added lubricant vs. equilibrium eccentricity, KRR and KRT top left and right, KTR and KTT bottom left and right, respectively. As shown all stiffness element increase by adding nanoparticles. Figure-16 depicts a maximum 16\% increase in stiffness, for 0.01 volume fraction of $\mathrm{Ag}$ to SAE engine oil.

Fig. 17 exposes the Stability graph, threshold angular velocity versus shaft rotation speed for increasing concentrations of nanoparticle added lubricant. As shown the critical velocity increases by increase of nanoparticles. Figure-17 depicts a 30\% increase in, threshold angular velocity for 0.01 volume fraction of nanoparticle to ordinary engine oil.

Fig. 18 unveils the Stability graph, threshold angular velocity versus eccentricity ratio for nanoparticle added lubricant. As shown, all mass elements, damping elements, stiffness elements, and the critical velocity increase by increase of nanoparticles volume fraction. It can be seeing from the results of Fig. 18 that nano-lubricants bargain advanced load carrying capacity at low volume fractions relative to usual oil. It is correspondingly seen that fluid film bearings at low shear requests are capable greater pressures relative to usual oil.

\section{Conclusions}

This paper has established an extension of Tichy and Bou-Said [1] work for examination of nano-lubricant films application counting time-based linearized turbulent inertia terms starting by Navier-Stokes equation. Based on the author's knowledge experimental consequences for using nano-fluid in bearings lubricating is not available to match the current results consequences to. As shown

- The critical velocity increases by increase of nanoparticles.

- Nano-lubricants bargain higher load capacity at low volume fractions relative to the usual oil.

- The inertia of the system is not affected significantly by the nano-particles while its stiffness and damping is increased by adding more nano-particles. 


\section{Nomenclature}

$c \quad$ Clearance in radial direction

(m)

$C_{x x}^{*} \quad$ dimensionless $x$ component of damping coefficient

$C_{y y}^{*} \quad$ dimensionless y component of damping coefficient

D Journal diameter

$e \quad$ eccentricity displacement in static condition

$\varepsilon=e / \mathrm{R} \quad$ eccentricity fraction

$F_{x u}, F_{y u} \quad$ un-balance forces

$F_{x}, F_{y}$

bearing forces

$F_{x}^{*}$

$\mathrm{x}$ component of dimensionless bearing force

$y$ component of dimensionless bearing force

$F_{y}^{*}$

lubricant film thickness

(m)

$h *=h / c \quad$ film thickness ratio

$K_{x x}^{*} \quad \mathrm{x}$ component of dimensionless stiffness coefficient

$K_{y y}^{*} \quad$ y component of dimensionless stiffness coefficient

$L \quad$ bearing length (m)

$m \quad$ total rotating shaft's mass

$M_{x x}^{*} \quad$ x component of dimensionless mass coefficient

$M^{*}{ }_{y y} \quad$ y component of dimensionless mass coefficient

$R \quad$ radius of shaft

$R e=(\omega c) \rho R / \mu$ Reynolds number based on journal clearance

$R e^{*}=(c / R) R e=\left(\omega c^{2}\right) \rho / \mu \quad$ modified Reynolds number,

$t \quad$ time elapsed

$U, V \quad \mathrm{x}$ (longitudinal) and y (radial) component of velocity of journal surface

$U_{p} \quad, W_{p} \quad \mathrm{z}$ (axial) and y (radial) component of average velocity of fluid

$(\mathrm{m} / \mathrm{s})$

$q_{x} \quad \mathrm{x}$ direction flow rate

$\left(\mathrm{m}^{2} / \mathrm{s}\right)$

$q_{\mathrm{z}} \quad \mathrm{z}$ direction flow rate

$I_{x x}, I_{x z}$, and $I_{z z}$ convective inertia variables $\left(\mathrm{m}^{3} / \mathrm{s} 2\right)$

$x, y$, and $z \quad$ components of Cartesian coordinate system

$X, Y$ components of center of shaft displacements

$X^{*}, Y^{*}$ dimensionless components of center of shaft displacements

$\omega$ shaft rotation speed

$U_{t}$ velocity components of translational in circumstance

$U_{r}$ velocity components of rotational in circumstance circumstance

$\mathbf{V}_{s}$ vector of velocity of shaft surface

$\mathbf{a}_{\mathrm{s}}$ vector of acceleration of shaft surface

$\theta \quad$ angular component of bearing coordinate position

$\left(\mathrm{m} / \mathrm{s}^{2}\right)$

$\tau_{x y}, \tau_{z y}$ fluid shear stress components

$\left(\mathrm{N} / \mathrm{m}^{2}\right)$

$\rho$ density of fluid

\section{Other Characteristic Parameters}

$$
\begin{aligned}
F_{x, y}^{*} & =\frac{c^{2}}{R L^{3}} \frac{F_{x, y}}{\mu \omega} \\
U_{r}^{*} & =\frac{U_{r}}{R \omega}=1,
\end{aligned}
$$


$\mathrm{p}^{*}=\frac{\mathrm{c}^{2}}{\mathrm{~L}^{2}} \frac{\mathrm{p}}{\mu \omega} \quad$ dimensionless pressure

$M^{*}=\left[M_{x x}^{*}, M_{x y}^{*} ; M_{y x}^{*}, M_{y y}^{*}\right]$ mass matrix

$\bar{m}=\left(\frac{c \cdot \omega^{2}}{W}\right) m \quad$ dimensionless mass

$W^{*}=\frac{c^{2}}{R L^{3}} \frac{W}{\mu \omega}$

\section{List of Figures}

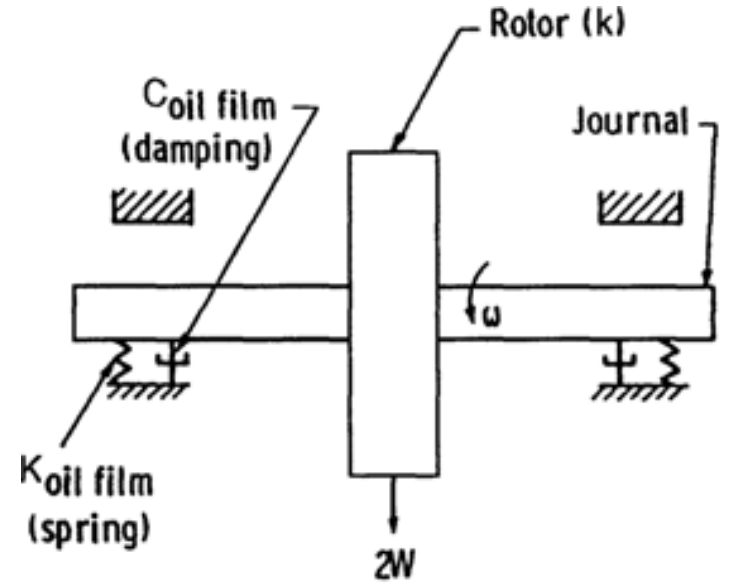

(a)

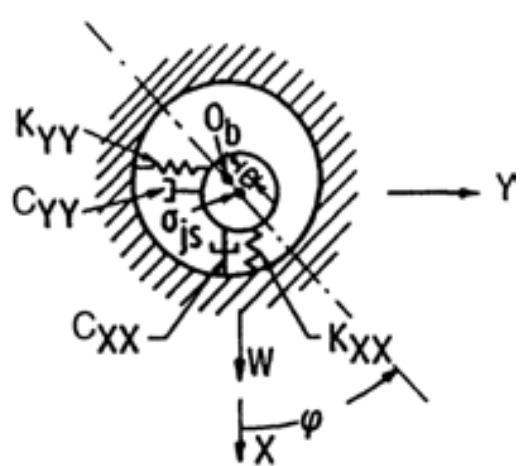

(b)

Figure 1. Dynamical elements of rotor-shaft configuration [2].

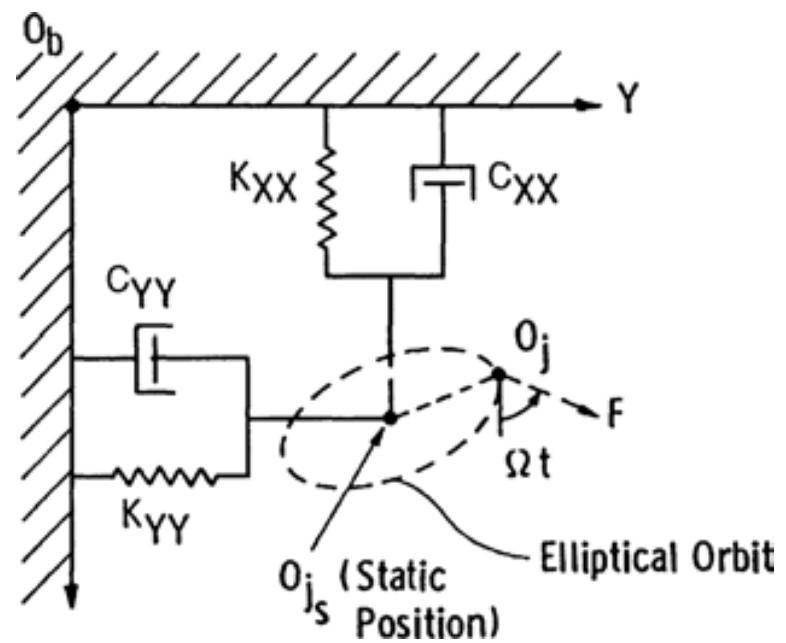

Figure 2. Representation of oil film as a simple dynamical system of springs and dampers [2]. 


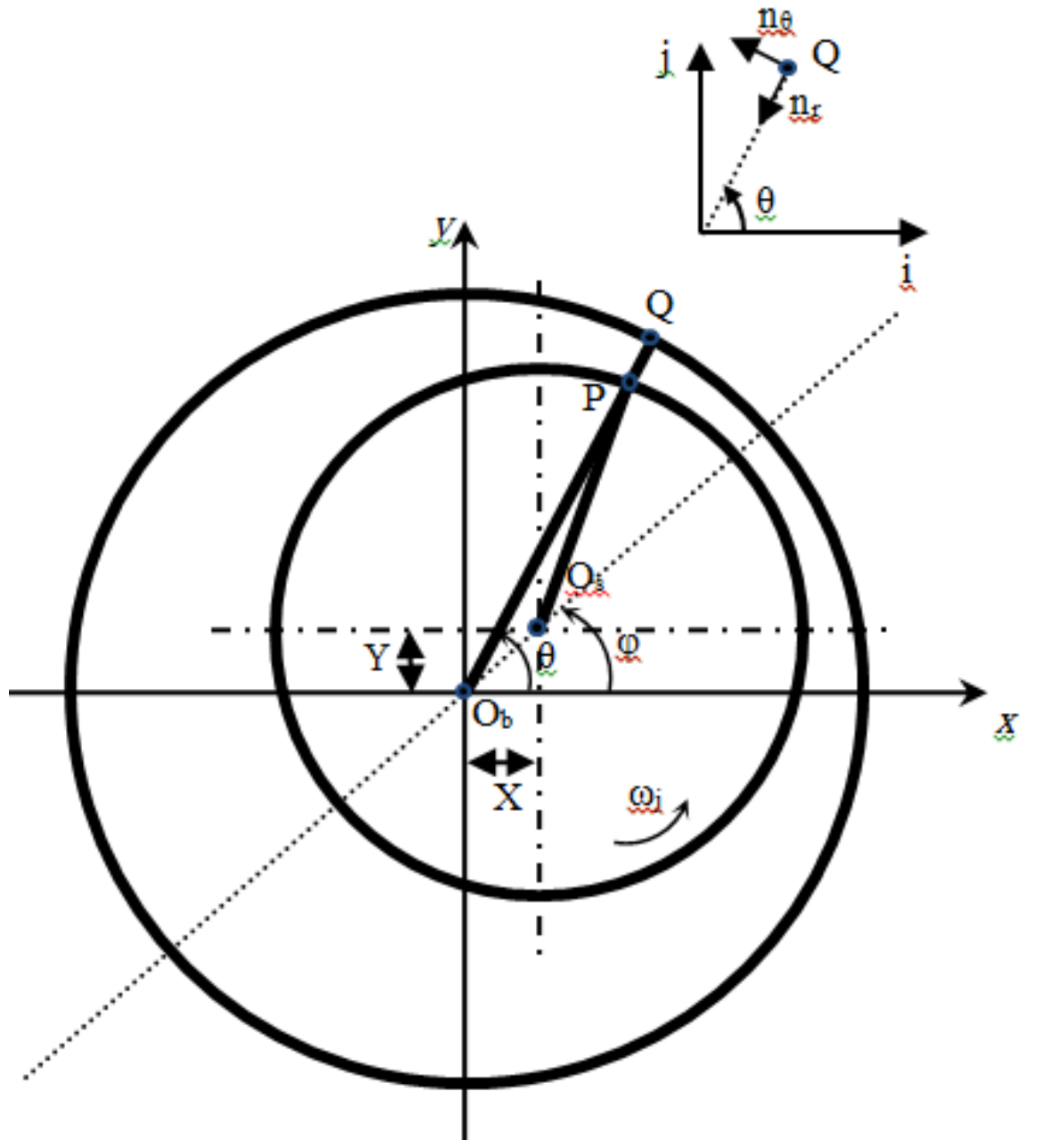

Figure 3. Plain Journal Bearing.
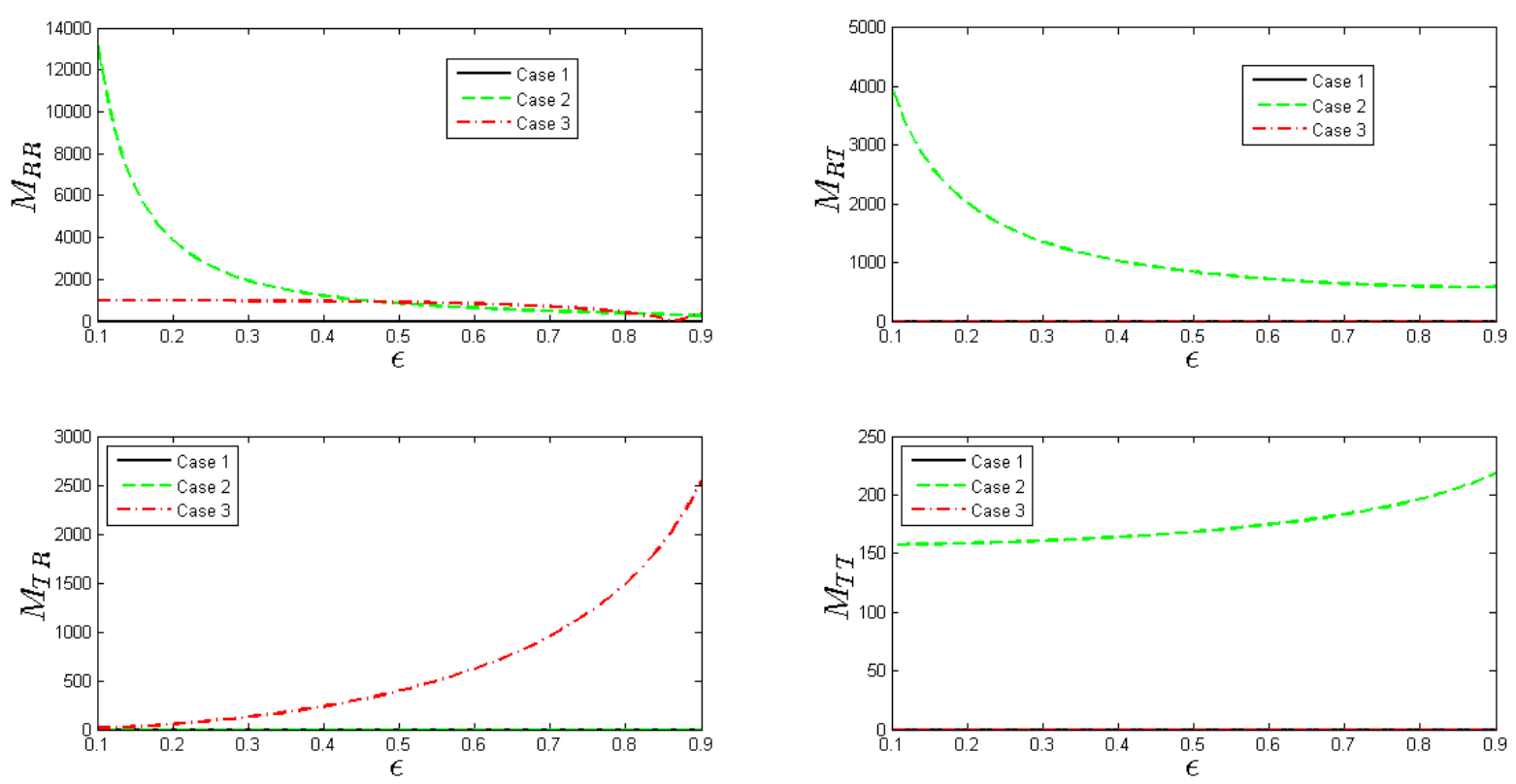

Figure 4. Added mass elements vs. equilibrium eccentricity, (a) $M_{R R}$, (b) $M_{R T}$, (c) $M_{T R}$ and (d) $M_{T T}$. 

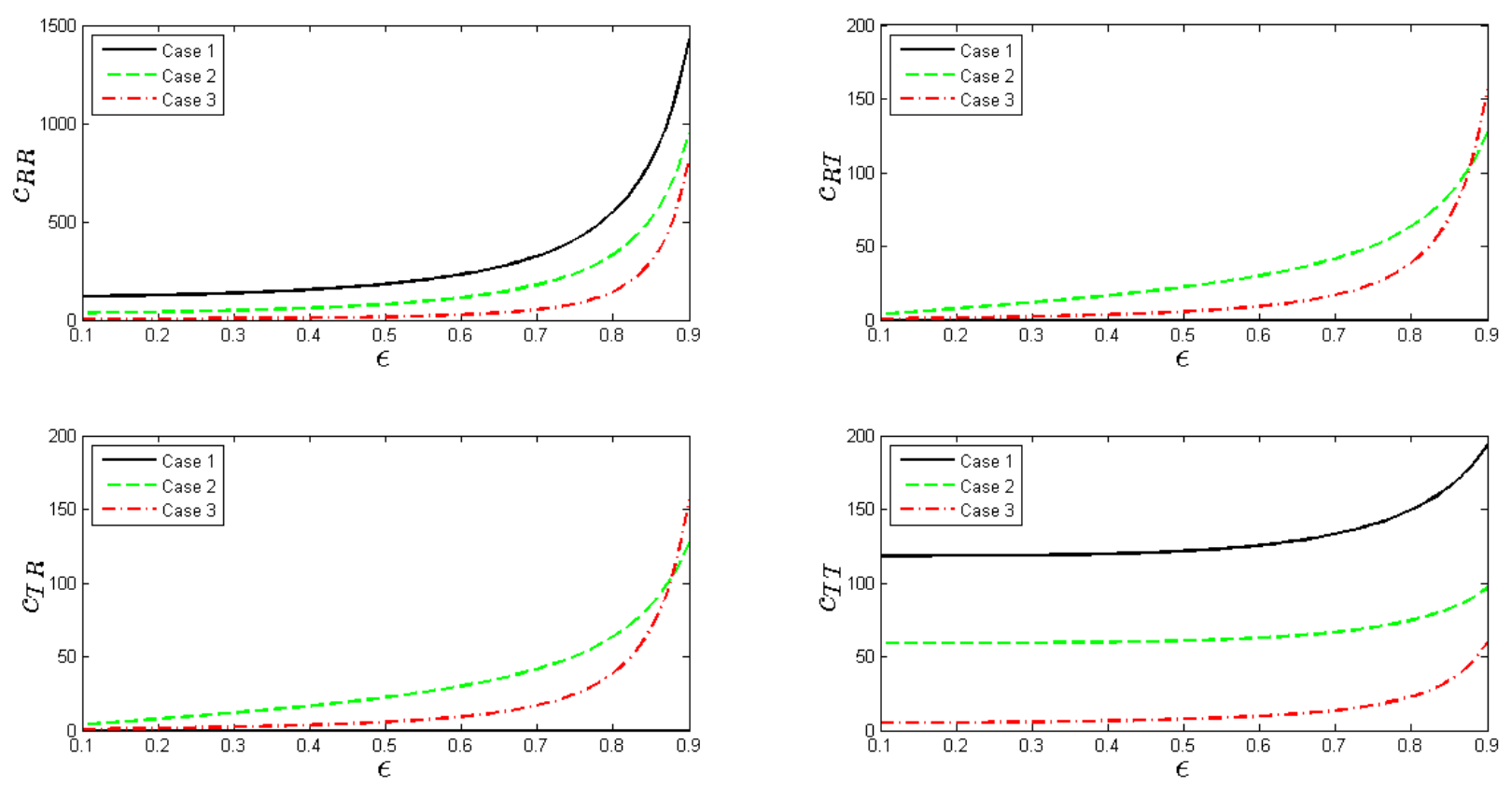

Figure 5. Damping elements vs. equilibrium eccentricity, (a) $C_{R R}$, (b) $C_{R T}$, (c) $C_{T R}$ and (d) $C_{T T}$.
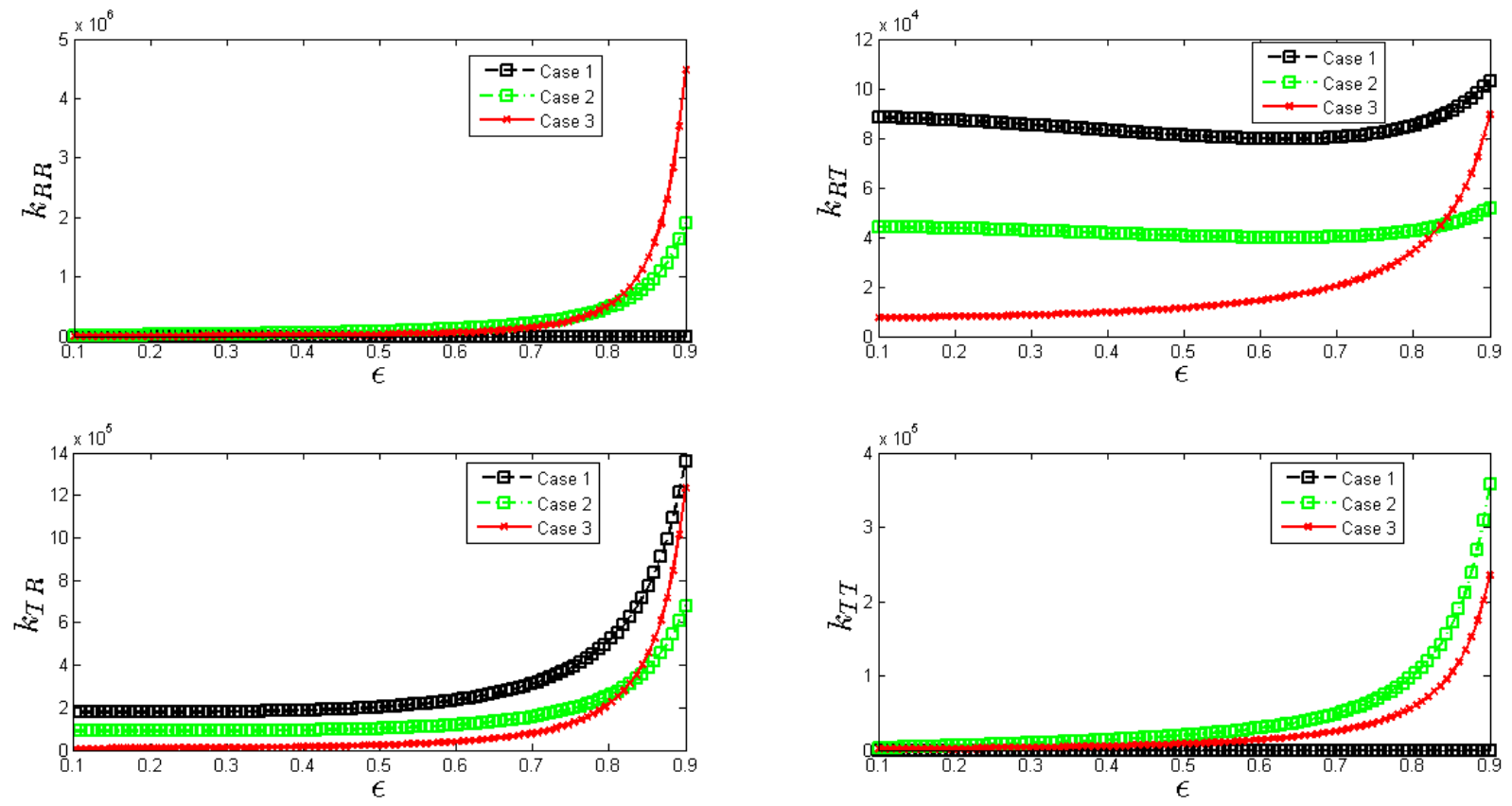

Figure 6. Stiffness elements vs. equilibrium eccentricity, (a) $K_{R R}$, (b) $K_{R T}$, (c) $K_{T R}$ and (d) $K_{T T}$. 


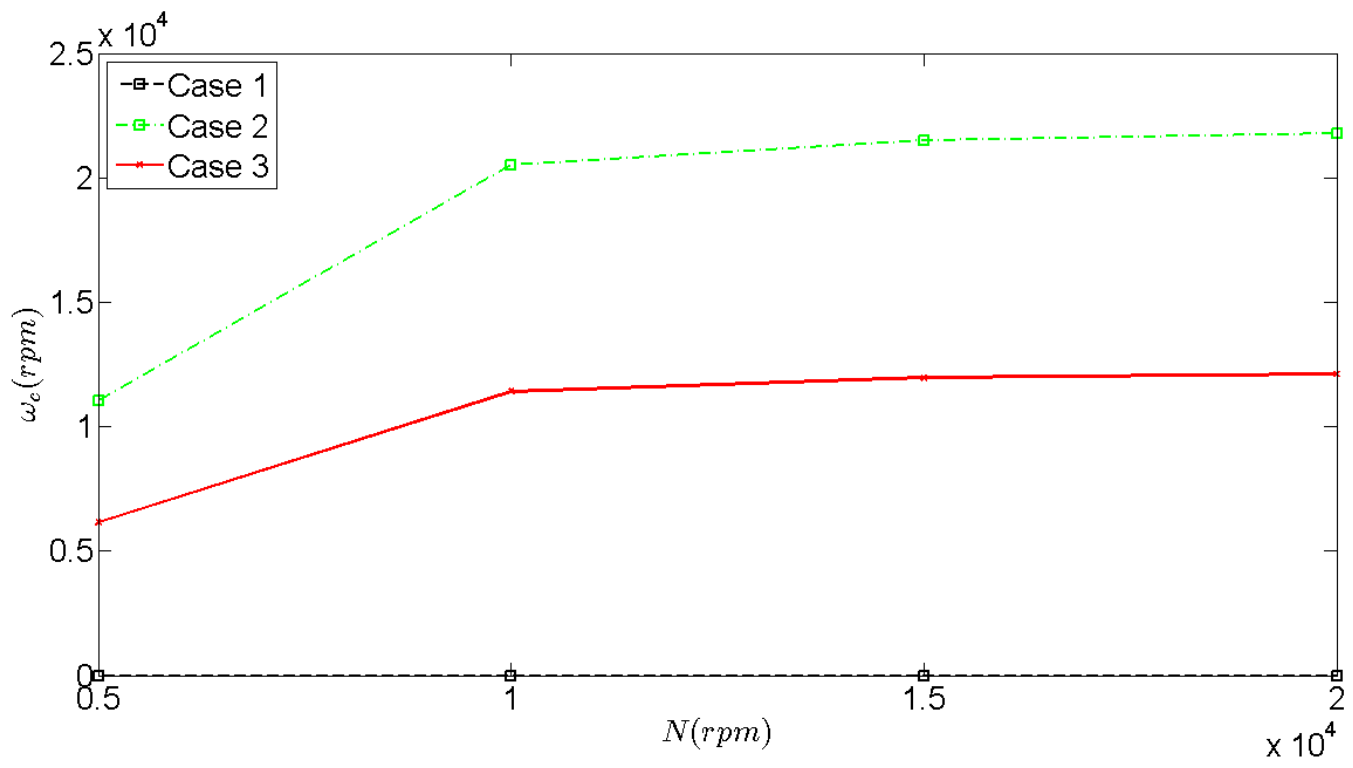

Figure 7. Stability graph, threshold angular velocity versus shaft rotation speed.

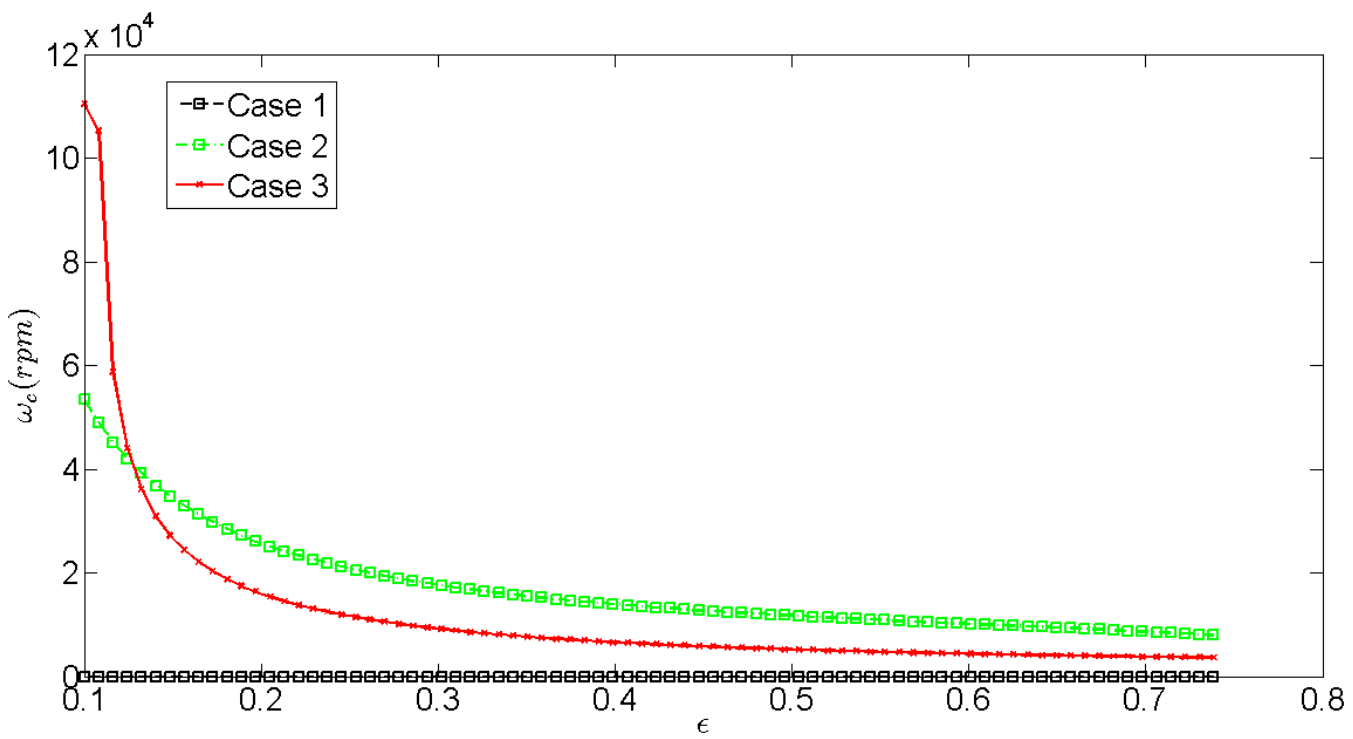

Figure 8. Stability graph, threshold angular velocity versus eccentricity ratio.

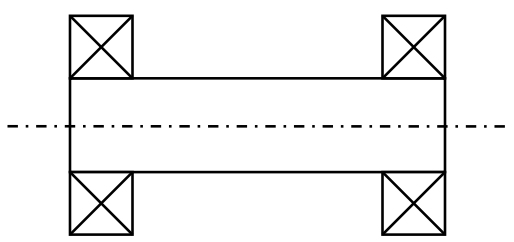

Figure 9. The rigid rotor supported with two short journal bearings. 

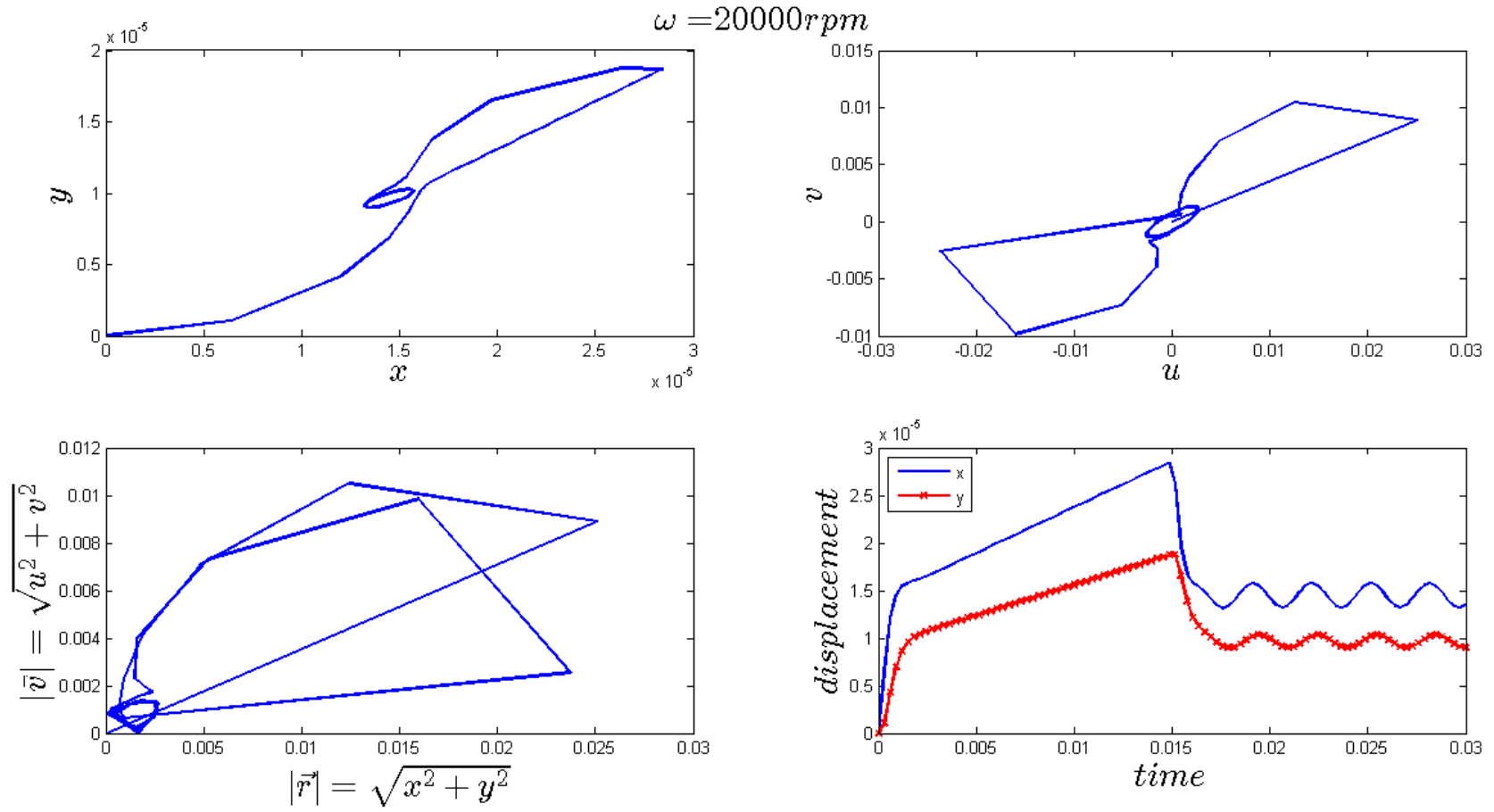

Figure 10. Orbits of the rigid rotor at bearing at 20000rpm in position space, velocity space, phase space, and displacement versus time.
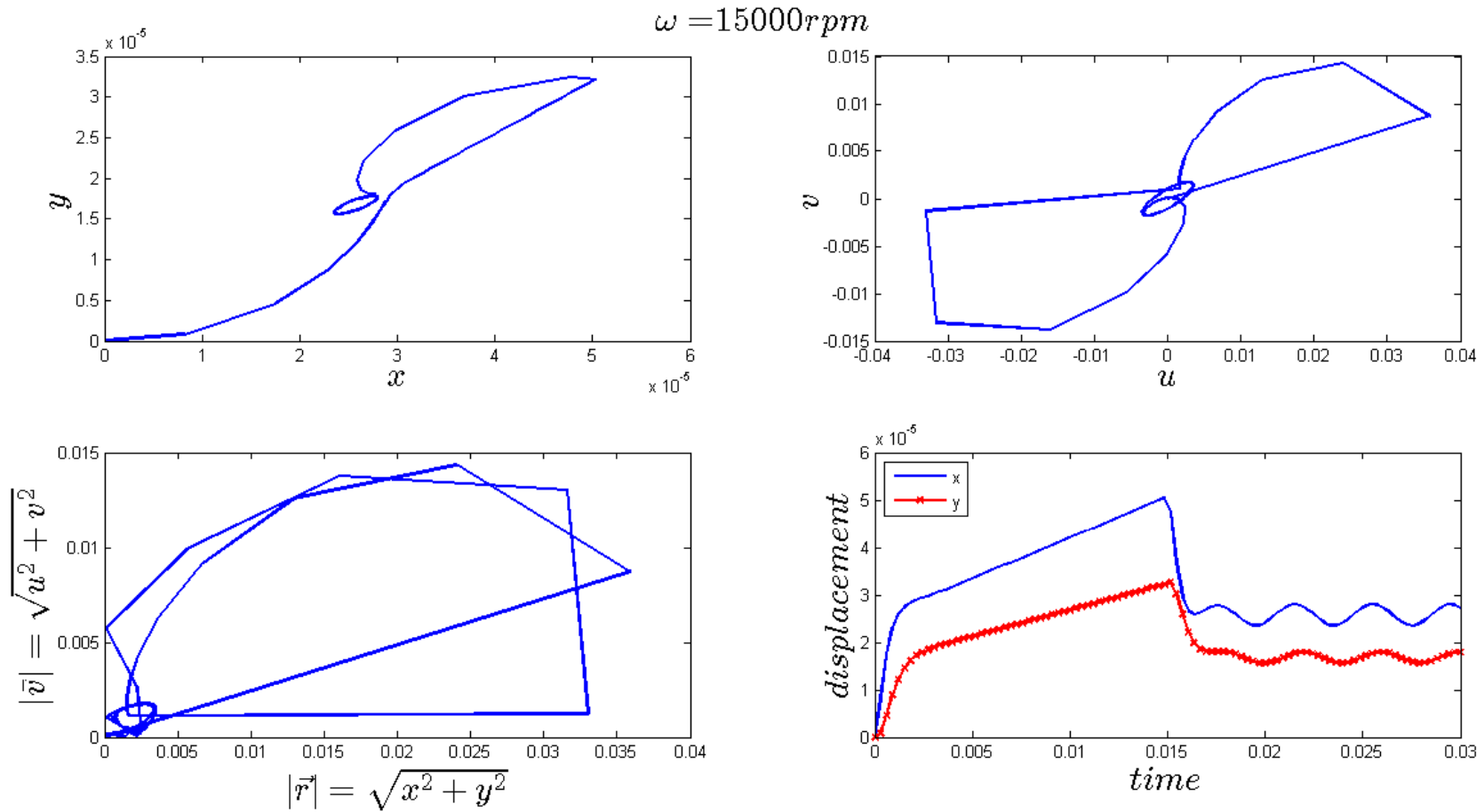

Figure 11. Orbits of the rigid rotor at bearing at 15000rpm in position space, velocity space, phase space, and displacement versus time. 

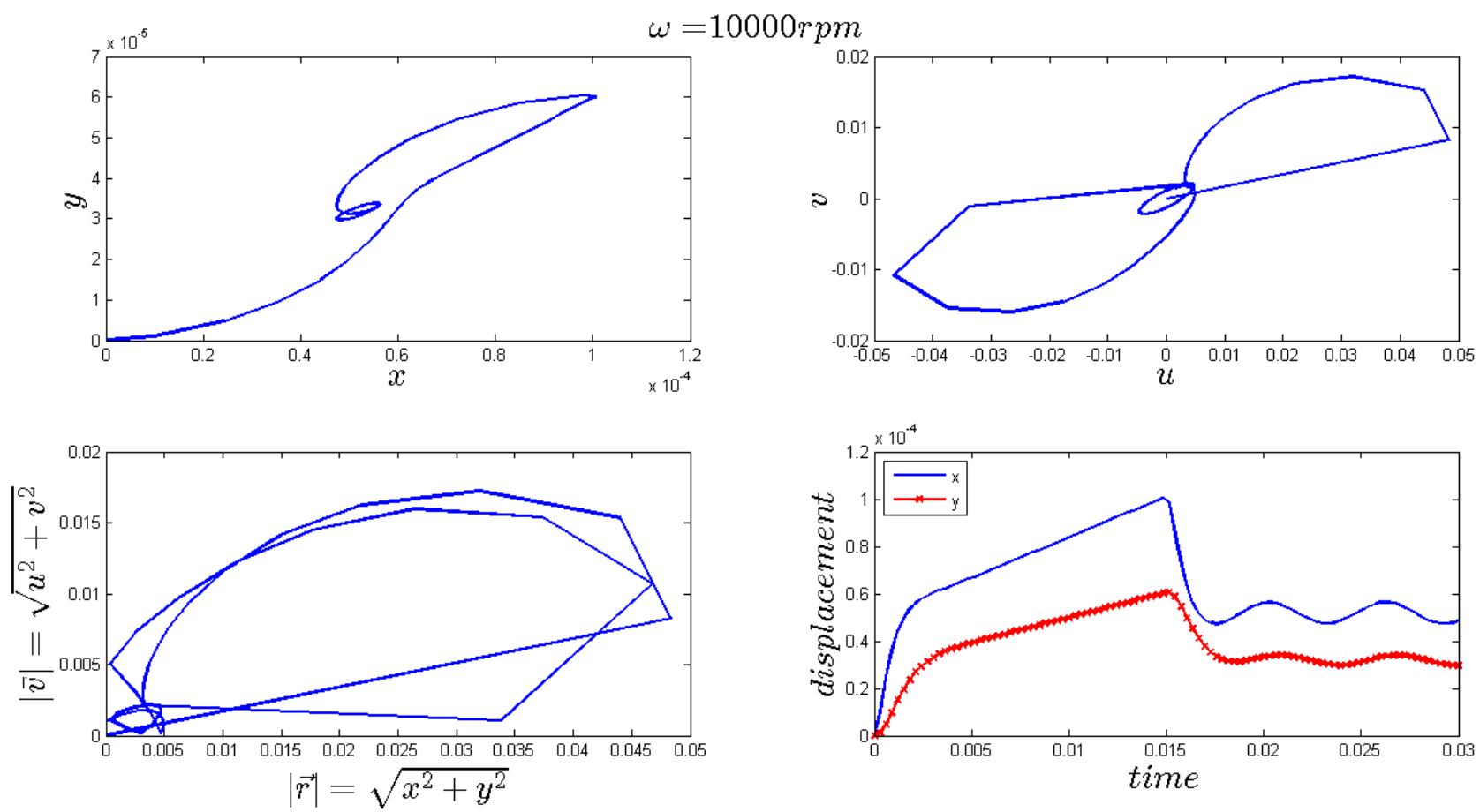

Figure 12. Orbits of the rigid rotor at bearing at 10000rpm in position space, velocity space, phase space, and displacement versus time.
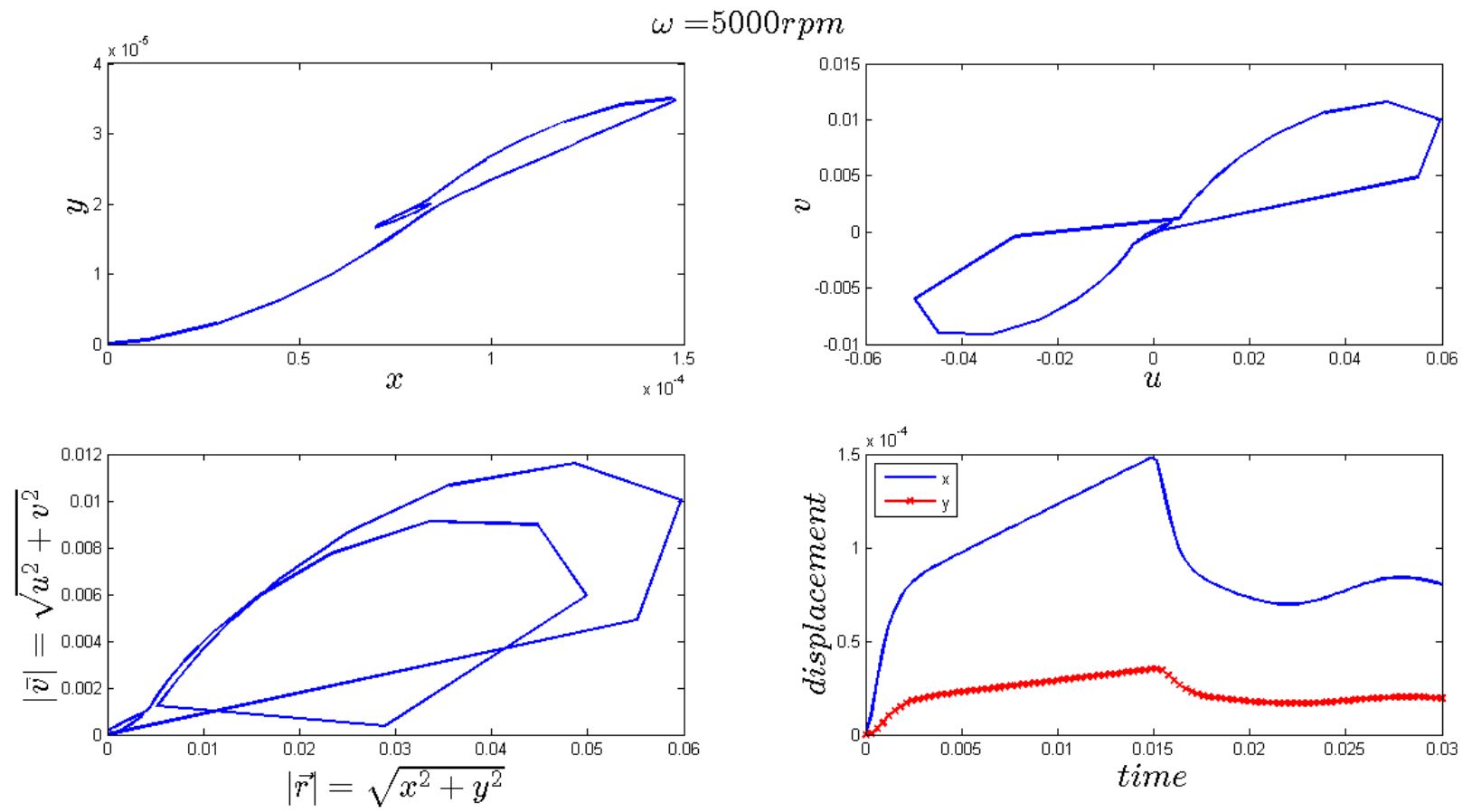

Figure 13. Orbits of the rigid rotor at bearing at 5000rpm in position space, velocity space, phase space, and displacement versus time. 

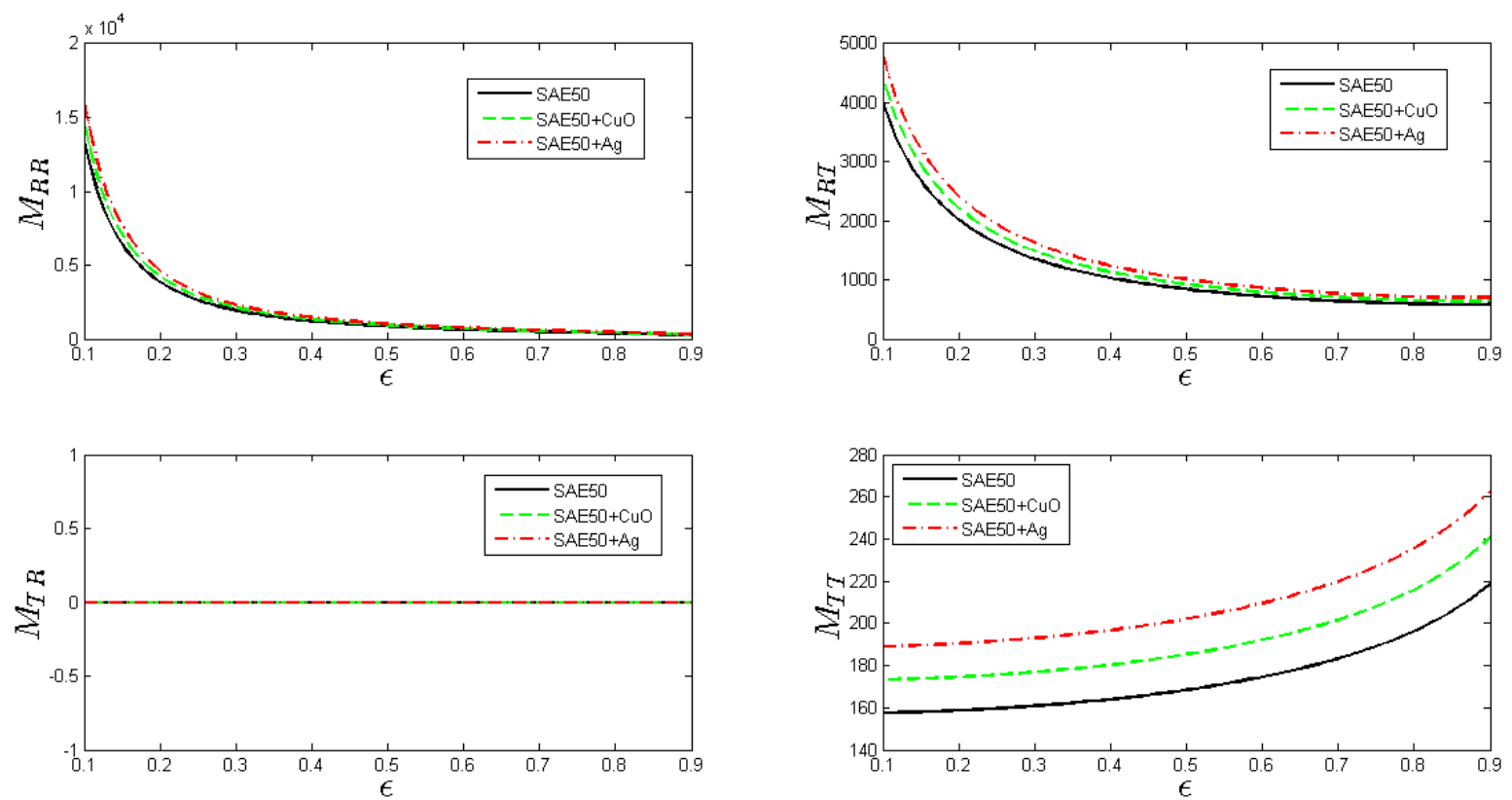

Figure 14. Added mass elements for nanoparticle added lubricant vs. equilibrium eccentricity, $M_{R R}$ and $M_{R T}$ top left and right, $M_{T R}$ and $M_{T T}$ bottom left and right, respectively.
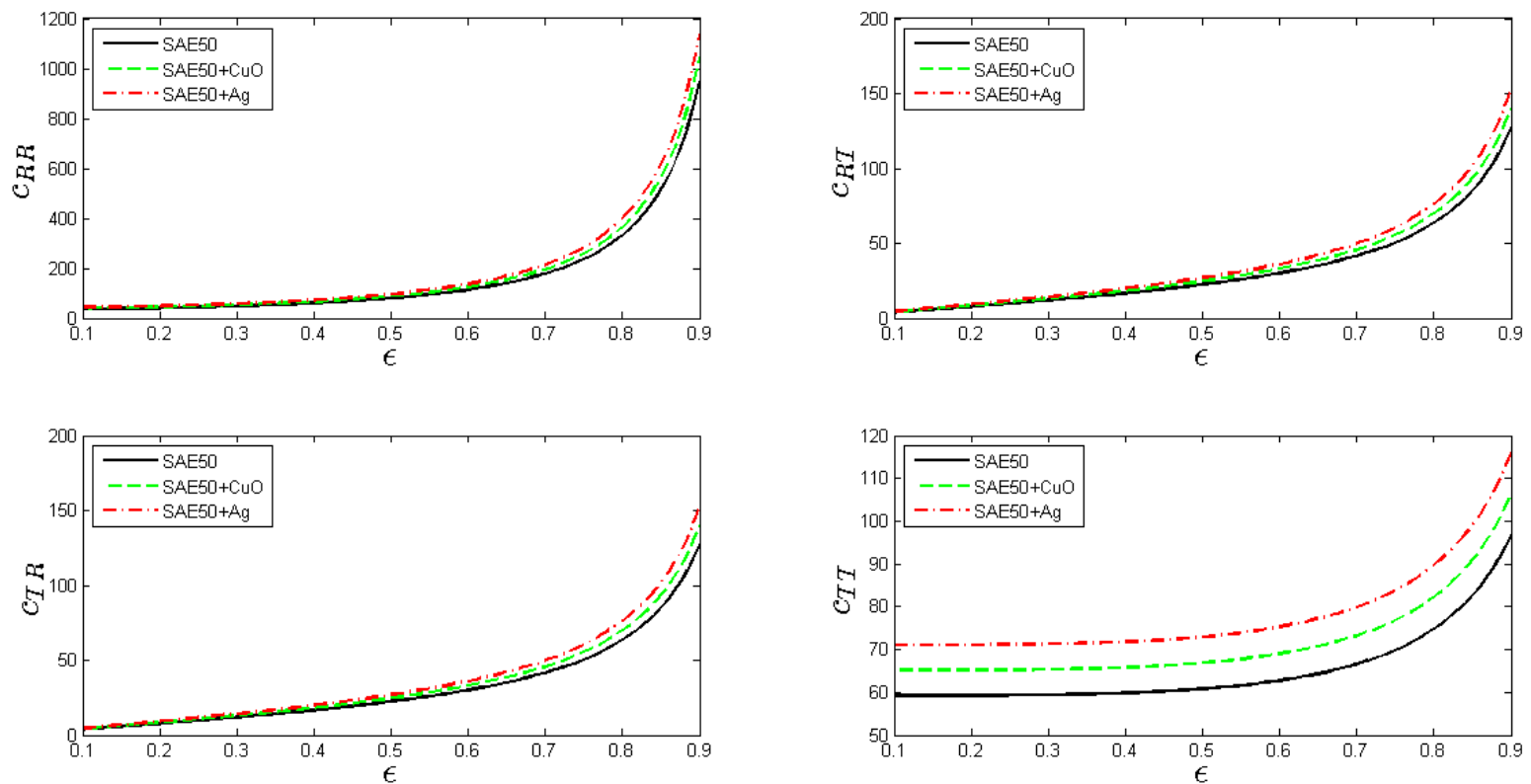

Figure 15. Damping elements for nanoparticle added lubricant vs. equilibrium eccentricity, $C_{R R}$ and $C_{R T}$ top left and right, $C_{T R}$ and $C_{T T}$ bottom left and right, respectively. 

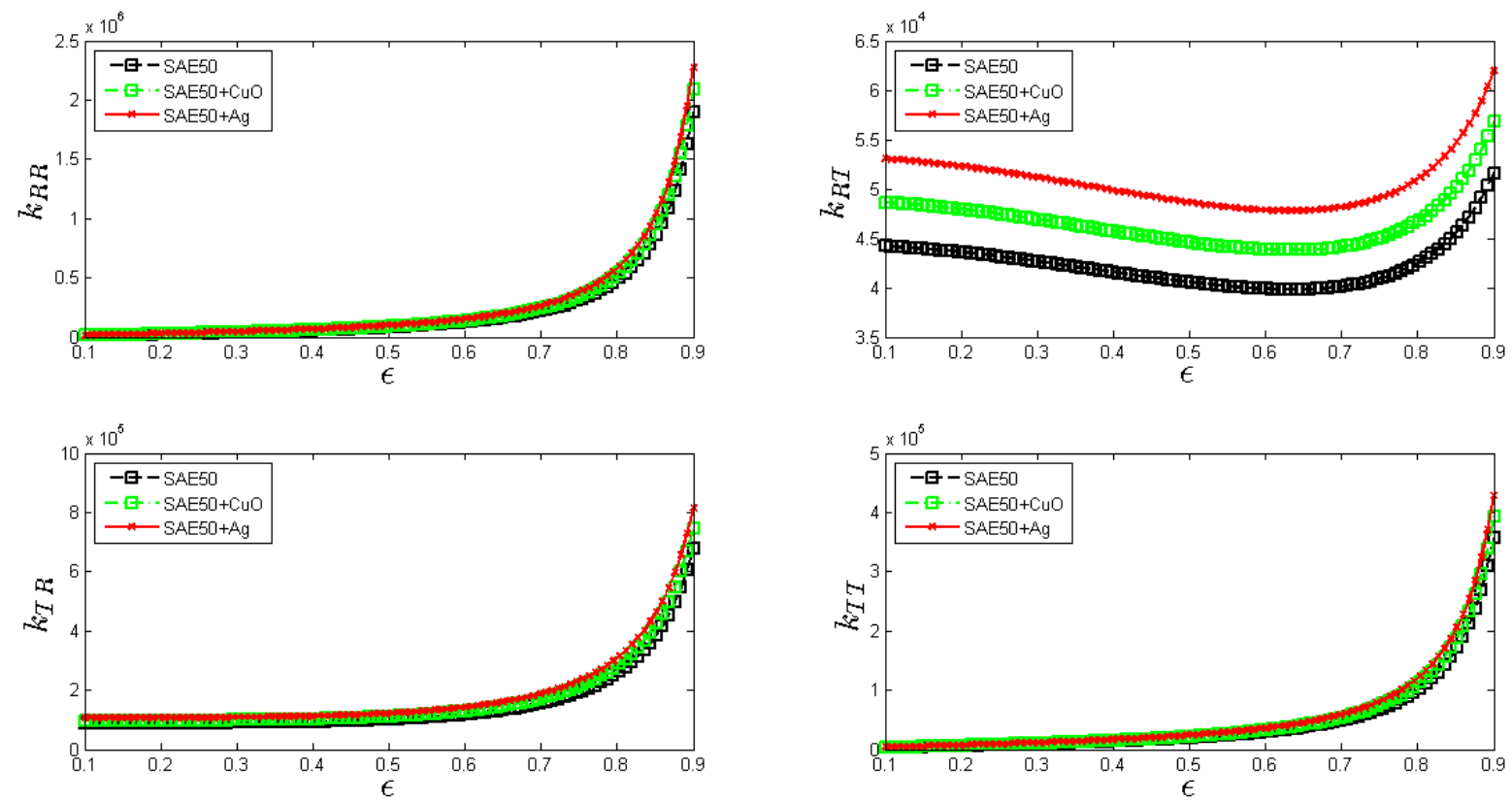

Figure 16. Stiffness elements for nanoparticle added lubricant vs. equilibrium eccentricity, (a) $K_{R R}$, (b) $K_{R T}$, (c) $K_{T R}$ and (d) $K_{T T}$.

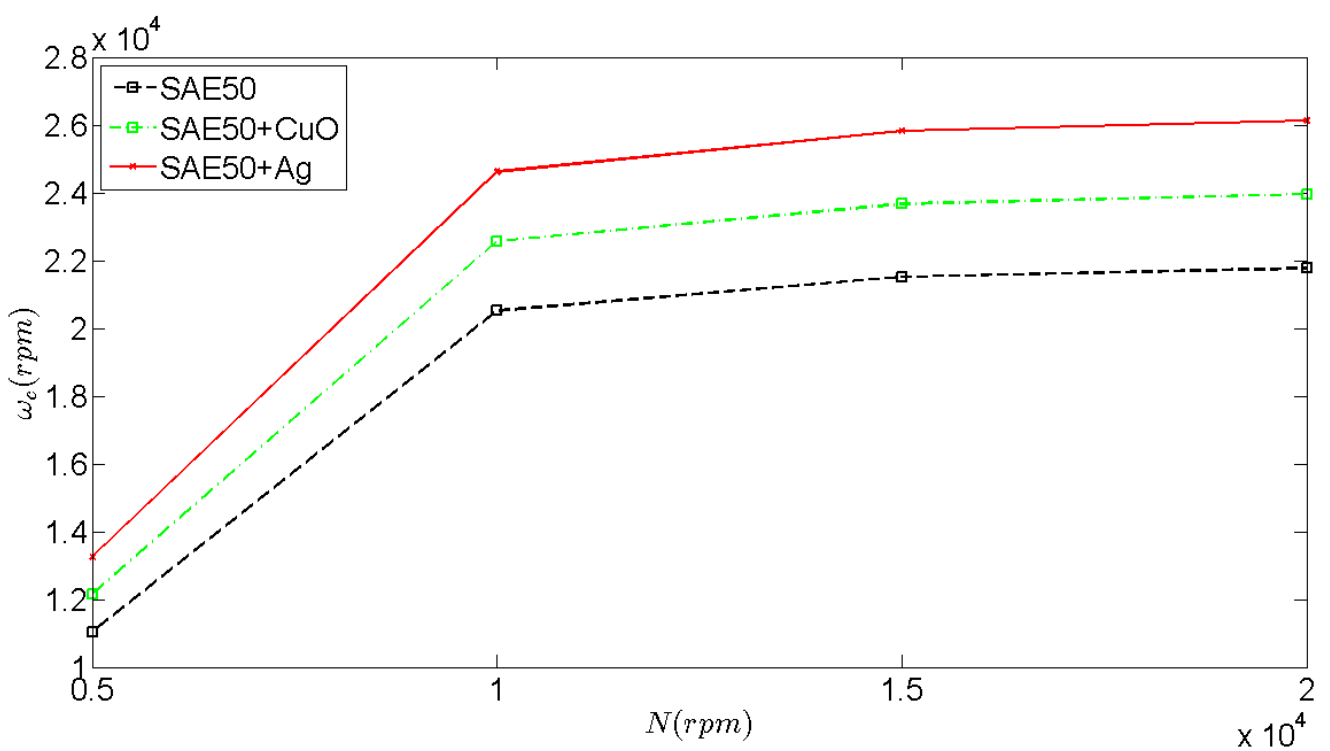

Figure 17. Stability graph, threshold angular velocity versus shaft rotation speed for nanoparticle added lubricant. 


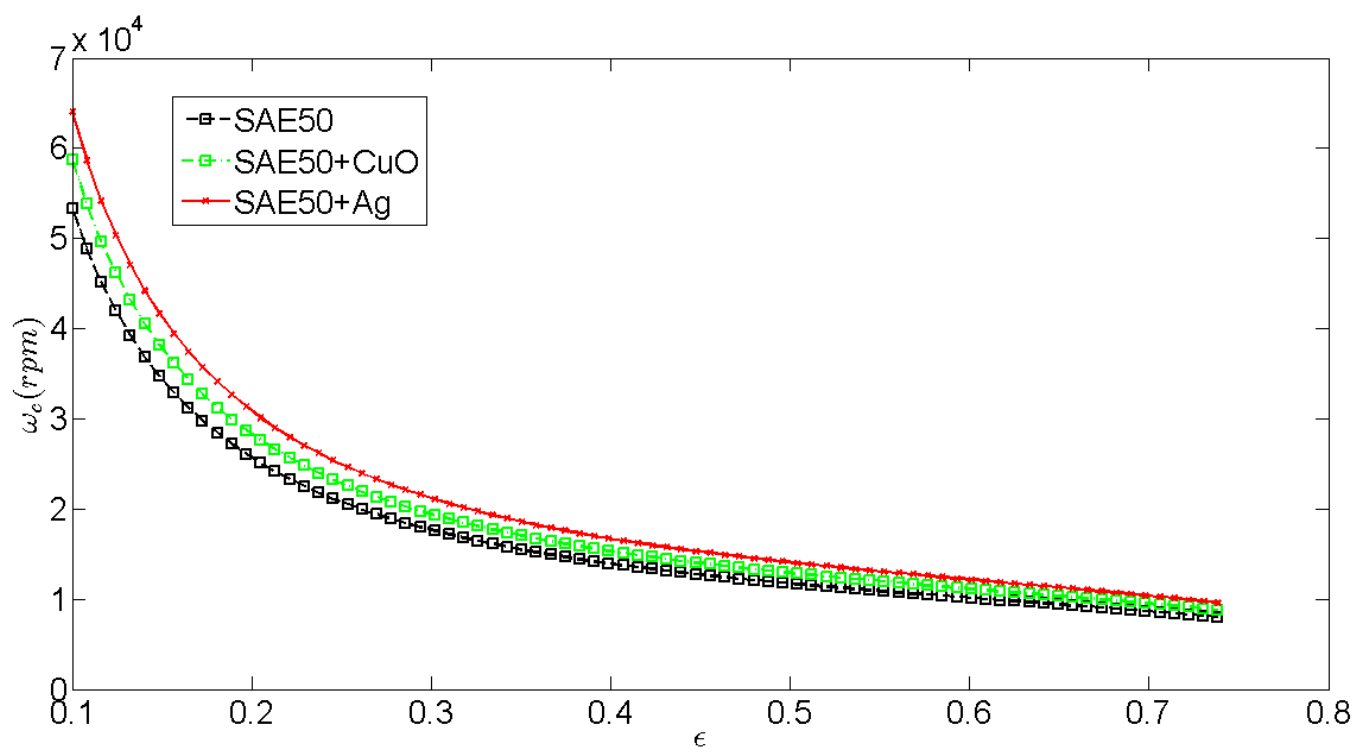

Figure 18. Stability graph, threshold angular velocity versus eccentricity ratio for nanoparticle added lubricant.

Table 1. Prosperities of the lubricant.

SAE 20W50

\begin{tabular}{ccc}
\hline Property & Value & Units \\
\hline Thermal conductivity & 0.14 & $\mathrm{~J} /\left(\mathrm{sec} \mathrm{m}{ }^{\circ} \mathrm{C}\right)$ \\
Heat of vaporization & 187 & $\mathrm{~kJ} / \mathrm{Kg}$ \\
Density & 880 at $16{ }^{\circ} \mathrm{C}$ & $\mathrm{kg} / \mathrm{m}^{3}$ \\
Viscosity & $8.94 \times 10^{-4}$ at $16{ }^{\circ} \mathrm{C}$ & $\mathrm{Pa.s}$ \\
Flash point & 243 & ${ }^{\circ} \mathrm{C}$ \\
Pour point & -23 & ${ }^{\circ} \mathrm{C}$ \\
\hline
\end{tabular}

Table 2. Thermo-physical properties of the nanoparticles.

\begin{tabular}{ccccc}
\hline $\begin{array}{c}\text { Thermo-physical } \\
\text { properties }\end{array}$ & $\mathrm{Ag}$ & $\mathrm{Cu}$ & $\mathrm{Cuo}$ & $\mathrm{TiO}_{2}$ \\
\hline$c_{p}(\mathrm{~J} / \mathrm{kg}-\mathrm{K})$ & 235 & 385 & 535.6 & 686.2 \\
$\rho\left(\mathrm{kg} / \mathrm{m}^{3}\right)$ & 10500 & 8933 & 6320 & 4250 \\
$k(\mathrm{~W} / \mathrm{m}-\mathrm{K})$ & 429 & 401 & 76.5 & 8.95 \\
$\beta \times 10^{-5}(1 / \mathrm{k})$ & 1.89 & 1.67 & 1.8 & 0.9 \\
$\mu($ pa.s $)$ & - & - & - & - \\
\hline
\end{tabular}


Table 3. Fix Pad Short Bearing geometry.

\begin{tabular}{ccc}
\hline Property & Value & Units \\
\hline Diameter & $100 \times 10^{-3}$ & $\mathrm{~m}$ \\
Radial Clearance & $0.12 \times 10^{-3}$ & $\mathrm{~m}$ \\
Length & $50 \times 10^{-3}$ & $\mathrm{~m}$ \\
\hline
\end{tabular}

Table 4. Transient analysis parameters for the rigid rotor.

\begin{tabular}{ccc}
\hline Property & Value & Units \\
\hline Rigid rotor & 40 & $\mathrm{~kg}$ \\
Unbalance Eccentricity & $6 \times 10^{-3}$ & $\mathrm{~kg} \mathrm{~m}$ \\
Operating speed & 1800 & $\mathrm{rpm}$ \\
Initial Time & 0 & $\mathrm{~s}$ \\
Final Time & 0.6 & $\mathrm{~s}$ \\
Time Step & $1 \times 10^{-4}$ & $\mathrm{~s}$ \\
\hline
\end{tabular}

\section{References}

[1] J. Tichy, B. Bou-Said, Hydrodynamic lubrication and bearing behavior with impulsive loads, Tribology Transactions. 34(4) (1991) 505-512.

[2] H. Hong et al., Nanogreases based on carbon nanotubes and commercial thickeners, NLGI Spokesman. 73(6) (2009) 23-32.

[3] H. Hong, A.J. Waynick, W. Roy, Nanogrease based on carbon nanotube, NLGI Spokesman. 72(7) (2008) 9.

[4] J. Chen, Tribological properties of polytetrafluoroethylene, nano-titanium dioxide, and nanosilicon dioxide as additives in mixed oil-based titanium complex grease, Tribology Letters. 38 (2010) 217-224.

[5] N. Canter, Friction-reducing characteristics of nano-boric acid, Tribology \& Lubrication Technology. 64(2) (2008) 10-11.

[6] A. Tomala et al., Effect of base oil polarity on micro and nanofriction behaviour of base oil + zddp solutions, Tribology - Materials, Surfaces \& Interfaces. 3(4) (2009) 182-188.

[7] H. Hong et al., Nanogreases based on carbon nanotubes and commercial thickeners, NLGI Spokesman. 73(6) (2009) 23-32.

[8] Nanotechnology: Untold promise, untold risk. Consumer Reports, 2007, pp. 40-45.

[9] G.L.X. Liu et al., Investigation of the mending effect and mechanism of copper nano-particles on a tribologically stressed surface, Tribology Letters. 17(4) (2004) 961-966.

[10] Y. Choi et al., Tribological behavior of copper nanoparticles as additives in oil, Current Applied Physics. 9 (2009) 124-127.

[11] C.G. Lee et al., A study on the tribological characteristics of graphite nano lubricants, International Journal of Precision Engineering and Manufacturing. 10(1) (2009) 85-90.

[12] G.R. Vakili-Nezhaad, A. Dorany, Investigation of the effect of multiwalled carbon nanotubes on the viscosity index of lube oil cuts, Chemical Engineering Communications. 196 (2009) 997-1007.

[13] J. Lee et al., Enhancement of lubrication properties of nano-oil by controlling the amount of fullerene nanoparticle additives, Tribology Letters. 28(2) (2007) 203-208.

[14] B.C. $\mathrm{Ku}$ et al., Tribological effects of fullerene (C60) nanoparticles added in mineral lubricants according to its viscosity, International journal of Precision Engineering and Manufacturing. 11(4) (2010) 607-611. 
[15] S.J. Lee et al., Application of fullerene-added nano-oil for lubrication enhancement in friction surfaces, Tribology International. 42 (2009) 440-447.

[16] X. Li, D. Zhu, X. Wang, Experimental investigation on viscosity of $\mathrm{Cu}-\mathrm{H} 2 \mathrm{O}$ nanofluids, Journal of Wuhan University of Technology-Mater. 24(1) (2009) 48-52.

[17] W. Li et al., Friction and wear properties of $\mathrm{ZrO} 2 / \mathrm{SiO} 2$ composite nanoparticles, Journal of Nanoparticles Research. 13 (2011) 2129-2137.

[18] Y. Wu, W. Tsuia, T. Liub, Experimental analysis of tribological properties of lubricating oils with nanoparticle additives, Wear. 262(7-8) (2007) 819-825.

[19] K. Lee et al., Understanding the role of nanoparticles in nano-oil lubrication, Tribology Letters. 35 (2009) 127-131.

[20] A.Z. Szeri, Fluid film lubrication theory and design, Cambridge University Press, Cambridge, 1998.

[21] O. Pinkus, B. Sternlicht, Theory of hydrodynamic lubrication, McGraw-Hill, New York, 1961.

[22] M.B. Banerjee et al., A nonlinear theory of hydrodynamic lubrication, Journal of Mathematical Analysis and Applications. 117(1) (1986) 48-56.

[23] C.-H. Chen, C.-K. Chen, The influence of fluid inertia on the operating characteristics of finite journal bearings, Wear. 131 (1989) 229-240.

[24] A.K. Tieu, Turbulence and inertia effects in finite width stepped thrust beaings, in: Proceedings of 13th Leeds-Lyon Symposium on Tribology, Fluid Film Lubrication - Osborne Reynolds Centenary, Eds. Dowson, Taylor, Godet, and Berthe, 1986, pp. 411-416.

[25] C.W. Ng, Fluid dynamic foundation of turbulent flow, ASLE Transactions. 7(4) (1964) 311 321.

[26] C.W. Ng, C.H.T. Pan, A linearized turbulent lubrication theory, Journal of Basic Engineering. 87(3) (1965) 675-682.

[27] H.G. Elrod, C.W. Ng, A theory for turbulent fluid films and its application to bearings, Journal of Lubrication Technology. 89(3) (1967) 346-362.

[28] V.N. Constaninescu, On the influence of inertial forces in turbulent and laminar self-acting films, Journal of Lubrication Technology. 93(2) (1970) 473-480.

[29] V.N. Constantinescu, S. Galetuse, On the possibilities of improving the accuracy of the evaluation of inertia forces in laminar and turbulent films, Journal of Lubrication Technology. 96(1) (1974) 69-77.

[30] V.N. Constantinescu, S. Galetuse, Operating characteristics of journal bearings in turbulent inertial flow, Journal of Lubrication Technology. 104(1) (1982) 173-179.

[31] A.Z. Szeri, A.A. Raimondi, A. Giron-Duarte, Linear force coefficients for squeeze-film dampers, Journal of Lubrication Technology. 105 (1983) 326-334.

[32] L. San Andrés, J. Vance, Effect of fluid inertia on finite length sealed squeeze film dampers, ASLE Transactions. 30(3) (1987) 384-393.

[33] E. Reinhardt, J.W. Lund, The influence of fluid inertia on the dynamic properties of journal bearings, Journal of Lubrication Technology. 97 (1975) 159-167.

[34] S.K. Kakoty, B.C. Majumdar, Effect of fluid inertia on stability of oil journal bearings, Journal of Tribology. 122(4) (2000) 741-745.

[35] P.E. Allaire, R.D. Flack, Journal bearing design for high speed turbomachinery, Bearing Design - Historical Aspects, Present Technology, and Future Problems, 1980, pp. 111-160. 
[36] R.D. Flack, P.E. Allaire, Instability Thresholds for Flexible Rotors in Hydrodynamic Bearings, in: Rotor Dynamic Instability Problems in High Performance Machines, Texas A\&M University, May 12-14, NASA Conference Publication 2133, 1980, pp. 403-427.

[37] B.C. Majumdar, D.E. Brewe, Stability of a rigid rotor supported on oil-film journal bearings under dynamic load, NASA Technical Memorandum 102309, AVS-COM, Technical Report 87-C-26, 1987, pp. 1-10.

[38] S. Dousti et al., Temporal and convective inertia effects in plain journal bearings with eccentricity, velocity and acceleration, Journal of Tribology. 134(3) (2012) 031704.

[39] S. Dousti et al., An extended reynold equation applicable to high reduced reynolds number operation of journal bearings, Tribology International. 102 (2016) 182-197.

[40] F. He et al., Squeeze film damper effect on vibration of an unbalanced flexible rotor using harmonic balance method, Journal of Engineering Science and Technology. 12(3) (2017) $667-685$.

[41] A. Kornaev et al., Influence of the ultrafine oil additives on friction and vibration in journal bearings, Tribology International. 101 (2016) 131-140.

[42] K.G. Binu et al., A variable viscosity approach for the evaluation of load carrying capacity of oil lubricated journal bearing with $\mathrm{TiO}_{2}$ nanoparticles as lubricant additives, Procedia Materials Science. 6 (2014) 1051-1067. 